Development, Validation and Feasibility Study of a Remote Basic Skills Assessment for Wheelchair Service Providers

by

\title{
Satria Ardianuari
}

B.S. in Prosthetics and Orthotics, Mahidol University of Thailand, 2016

\author{
Submitted to the Graduate Faculty of the \\ School of Health and Rehabilitation Sciences in partial fulfillment \\ of the requirements for the degree of \\ Master of Science
}

University of Pittsburgh 


\title{
UNIVERSITY OF PITTSBURGH
}

\section{SCHOOL OF HEALTH AND REHABILITATION SCIENCES}

This thesis was presented

by

\section{Satria Ardianuari}

\author{
It was defended on
}

March 11, 2020

and approved by

Jonathan Pearlman, Ph.D., Associate Professor, Department of Rehabilitation Science and Technology, University of Pittsburgh, International Society of Wheelchair Professionals

Mark Schmeler, Ph.D., OTR/L, ATP, Associate Professor, Department of Rehabilitation Science and Technology, University of Pittsburgh

Thesis Advisor: Mary Goldberg, Ph.D., Associate Professor, Department of Rehabilitation Science and Technology, University of Pittsburgh, Human Engineering Research Laboratories, International Society of Wheelchair Professionals 
Copyright $(\mathrm{C}$ by Satria Ardianuari

2020 


\title{
Development, Validation and Feasibility Study of a Remote Basic Skills Assessment for Wheelchair Service Providers
}

\author{
Satria Ardianuari, BSPO, MS \\ University of Pittsburgh, 2020
}

The purpose of this study was to develop, validate and conduct a feasibility study of three remote basic skills assessment modalities for wheelchair service providers (WSP) including an online mock-client case study quiz (m1), an in-person skills assessment $(\mathrm{m} 2)$ and a video conference skills assessment (m3). Prior to this study, we were unaware of a validated remote basic skills assessment for WSP that reflects all WHO 8 wheelchair service provision steps. Such a test may be an asset to training or professional organizations like the International Society of Wheelchair Professionals (ISWP) as a way to test provider competency or to warrant certification. Currently, we are unaware of any certification that includes a skills test as a requirement.

Our first hypothesis was that all three modalities are comparable as evidenced by the mean score of ISWP Basic Knowledge Test (i.e., within one SD). Our second hypothesis was that all modalities were feasible according to seven defined feasibility criteria. Inclusion criteria included passing the ISWP Basic Knowledge Test. We recruited a total of 12 participants; all completed $\mathrm{m} 1$. Five completed $\mathrm{m} 2$ at the 35th International Seating Symposium and five completed m3 via Adobe Connect. Two participants dropped out of the study prior to completing a second testing modality.

The results show that our first hypothesis was rejected because only $\mathrm{m} 1$ mean score was comparable to the ISWP Basic Knowledge Test (SD =.44). This is in contrast with the Wilcoxon 
signed-rank test results that show a statistically significant difference between these two modalities. Hypothesis two was not rejected. The feasibility results reveal that all three modalities met the minimum criteria ( $86 \%$ success). Thus, based on this finding, $\mathrm{m} 1,2$ and 3 have the potential to serve as remote basic skills assessments through ISWP or other training or credentialing organizations. However, according to both test performance and feasibility criteria, the study team and participants encountered the fewest challenges with $\mathrm{m} 2$, and therefore, we believe this assessment has the highest potential to be included in the ISWP WSP basic skills certification process to ensure fidelity to practice. 
Table of Contents

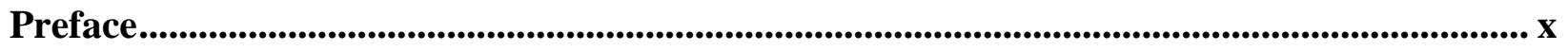

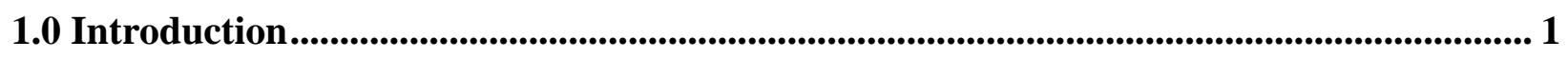

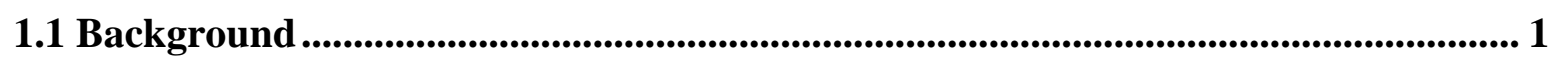

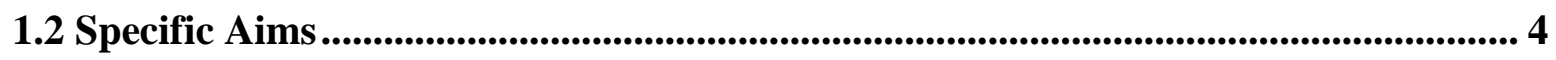

1.3 Hypotheses....................................................................................................................................... 4

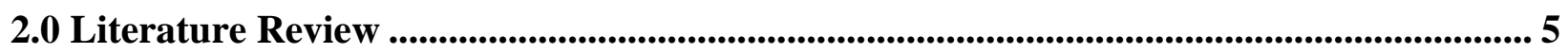

2.1 Global Capacity Building for Wheelchair Service Providers.................................... 5

2.2 Testing Approaches for Rehabilitation Professionals' Knowledge and Skills.......... 7

2.2.1 Remote Skills Test Approaches........................................................................ 8

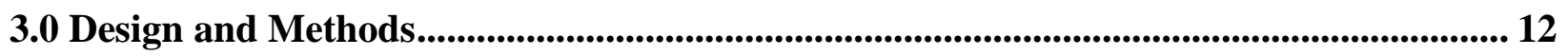

3.1 Specific Aim 1: Development and Validation of Modality 1 ................................... 12

3.1.1 Content Generation.............................................................................................. 12

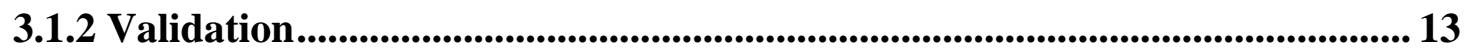

3.2 Specific Aim 2: Development and Validation of Standard Rubric and Protocols for

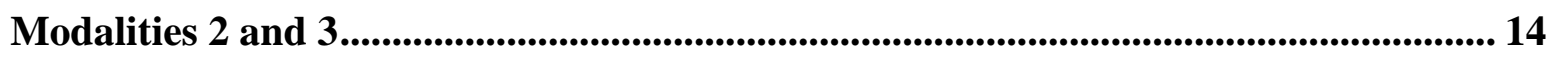

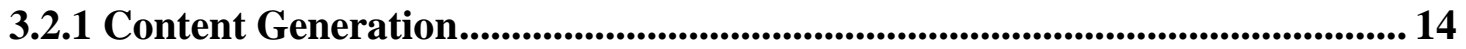

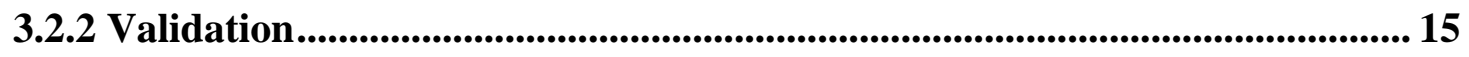

3.3 Specific Aim 3: Feasibility Test ............................................................................................ 16

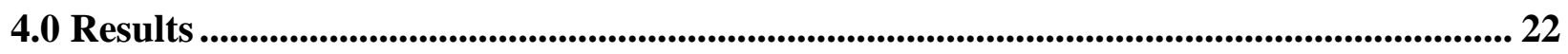

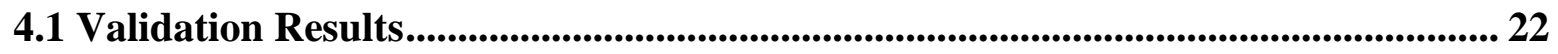

4.1.1 Modality 1 ....................................................................................................................... 22 


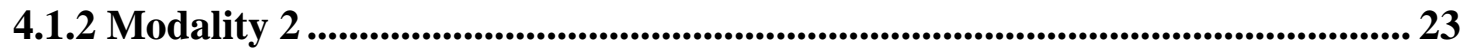

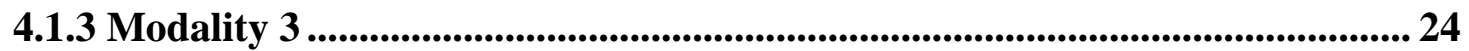

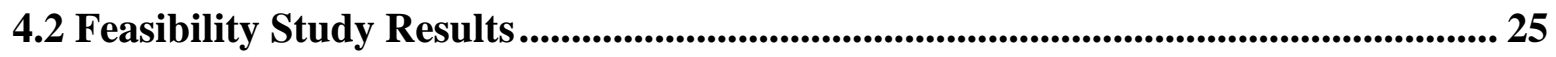

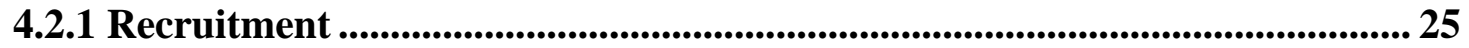

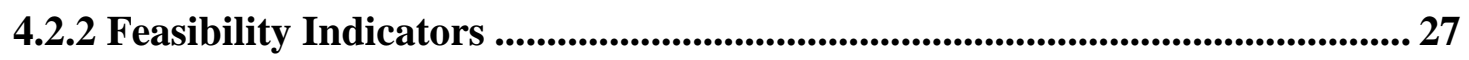

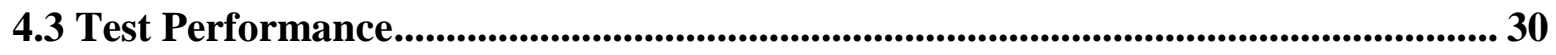

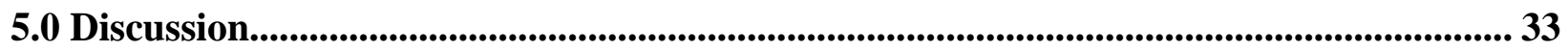

5.1 Three Modalities Have Potential to Serve as a Universal Skills Test ....................... 33

5.2 Potential Barriers and Facilitators of Testing Modalities ...................................... 35

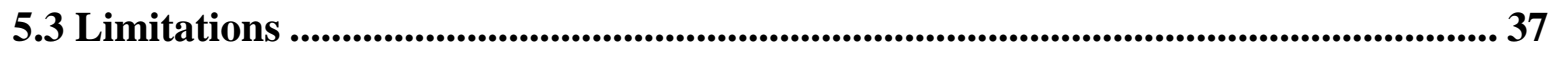

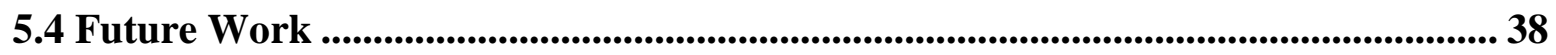

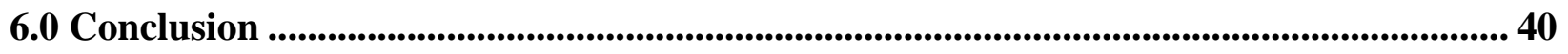

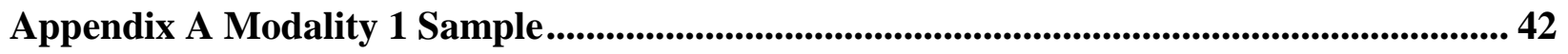

Appendix B Modality 2 Protocol ................................................................................................... 45

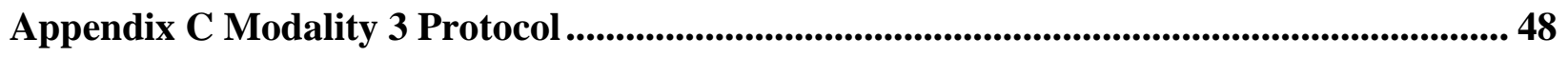

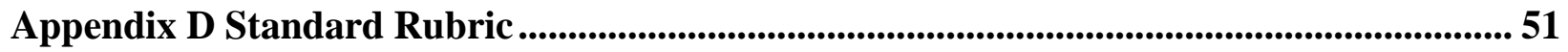

Appendix E WHO Forms .......................................................................................................................... 57

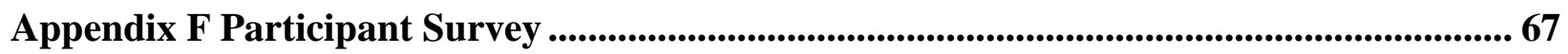

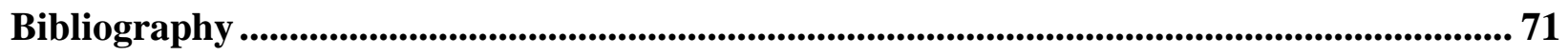




\section{List of Tables}

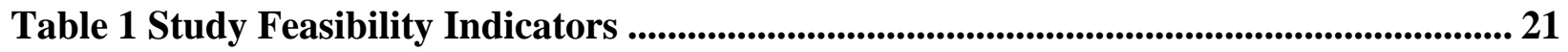

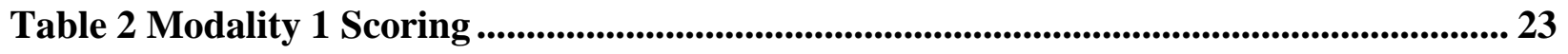

Table 3 Baseline of Participant Demographics ......................................................................... 26

Table 4 Participant Individual Testing Times.................................................................... 28

Table 5 Results of Study Feasibility Indicators................................................................. 29

Table 6 Mean Score and Standard Deviation Comparison across All Modalities................. 30

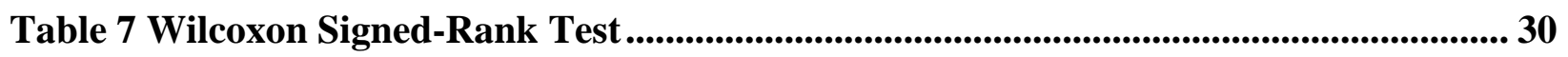




\section{List of Figures}

Figure 1 Modality 1 Development Process ........................................................................ 13

Figure 2 Development and Feasibility Test of All Modalities............................................... 17

Figure 3 Online Quiz on ISWP WIN................................................................................................. 19

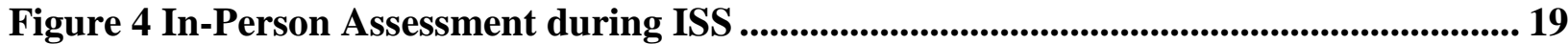

Figure 5 Video Conference on Adobe Connect .......................................................................... 20

Figure 6 Flow of Participants......................................................................................................... 25

Figure 7 Modalities 1 and 2 Individual Score Comparison ................................................. 31

Figure 8 Modalities 1 and 3 Individual Score Comparison ....................................................... 32 


\section{Preface}

This thesis would not have been possible without the help and support from the following people.

To start I would like to thank Dr. Mary Goldberg, my advisor for her guidance and mentorship. I would like to thank ISWP personnel, especially Krithika Kandavel, Nancy Augustine and Kimberly Robinson for their help during the process of data collection. I would also like to thank my thesis committee, Drs. Jonathan Pearlman and Mark Schmeler for all their enthusiasm, suggestions and constructive criticism. Last but not least, I would like to thank all the participants, client models and moderators for their participation.

This study was supported by the Paralyzed Veterans of America (PVA) and the International Society of Wheelchair Professionals (ISWP) (funding from U.S. Agency for International Development (USAID) under sub-awards Agreement No. APC-GM-0068 and Agreement No. APC-GM-0107, presented by Advancing Partners \& Communities, a cooperative agreement funded through USAID under Agreement No. AIDOAA-A-12-00047, beginning Oct. 1, 2012; and FY19-A01-6024, presented through University Research Co. LLC Health Evaluation and Applied Research Development (HEARD) Project. HEARD is funded by USAID under cooperative agreement number AID-OAA-A-17-00002. The project team includes prime recipient, University Research Co., LLC (URC) and sub-recipient organizations). The preliminary results of the study were presented at the PVA Healthcare Summit + Expo: August 15 - 17, 2019 in Florida. 


\subsection{Introduction}

\subsection{Background}

According to the World Health Survey (2002-2004), approximately 785 million (15.6\%) persons $\geq 15$ years live with a disability, while the Global Burden of Disease estimates a figure of approximately 975 million (19.4\%) persons. Of these, the World Health Survey estimates that 110 million people $(2.2 \%)$ have very significant difficulties in functioning, while the Global Burden of Disease estimates that 190 million (3.8\%) have severe disability including those that impair mobility (World Health Organization (WHO) World Report on Disability, 2011). The United Nations Convention on the Rights of Persons with Disabilities (UNCRPD) provides the general principles of accessibility (including rehabilitation) as a means to the empowerment and inclusion for people with disabilities and mandates mobility as a human right for all (UNCRPD, 2006). For people with impaired mobility, wheelchairs are one of the most important assistive technology (AT) devices to improve functioning and independence and thereby promote overall well-being (WHO Priority Assistive Products List, 2016 \& Kirby et al., 2002). In fact, an estimated 70 million people use or need wheelchairs worldwide (WHO, 2018).

However, according to ATscale, a global partnership initiative for AT launched in 2018, lack of and/or untrained workforce and inappropriate AT (including wheelchair) products and services were identified as barriers to be tackled to achieve better access to AT worldwide (ATscale, 2018). Additionally, the 2018 Wheelchair Stakeholders' Meeting in India proposed ten priority actions to strategize for a future with greater access to appropriate wheelchairs. The priority actions included establishing wheelchair service standards for individual service provider 
(i.e., certification) and implementing a global campaign on the benefits of appropriate wheelchair provision (USAID, 2018).

Properly prescribed wheelchairs allow people with impaired mobility to gain increased ability to perform ADLs, participate in communities, and reduce secondary medical complications such as upper limb repetitive strain injuries, pain, and/or pressure sores (Mills et al., 2007, Chaves et al., 2004, Boninger et al., 2007, Crane et al., 2003, \& Geyer, 2001). Therefore, providers' clinical knowledge and skills are essential for the prescription of an appropriate wheelchair to avoid physical harm, abandonment of the device and unnecessary expenses. Capacity building and proper certification of wheelchair providers can assist in combating under/over prescriptions (Toro et al., 2016 \& Greer et al., 2012).

The WHO has made initial strides in developing the guidelines on the provision of wheelchairs in less-resourced settings (2008), Wheelchair Service Training Packages (2012; 2013; 2015) and Wheelchair Service Training of Trainers Package (2017). Despite the availability of open-source materials, we know that pre-professional academic rehabilitation curricula include variable content related to wheelchairs (Fung et al., 2019) and informal inperson trainings offered by NGOs may be difficult to scale across multiple settings.

The International Society of Wheelchair Professionals (ISWP) has initiated several efforts to fill this gap by developing materials and approaches to improve and standardize wheelchair knowledge and skills (Goldberg et al., 2013, Goldberg, 2014, Gartz et al., 2017, Fung et al., 2017, Munera et al., 2017, Mendez et al., 2018, Goldberg et al., 2018, Hernandez et al., 2019, Gowran et al., 2019, Burrola et al., 2019, Fung et al., 2019 \& Rushton et al., 2020). ISWP has been involved with the development and review of the WHO Wheelchair Service Training Packages (WSTP) (Goldberg et al., 2013, Goldberg, 2014, Gartz et al., 2017, Fung et al., 2017, 
Munera et al., 2017, Mendez et al., 2018, Goldberg et al., 2018, Hernandez et al., 2019, Gowran et al., 2019, Mendez et al., 2019, \& Fung et al., 2019). WSTP outline essential basic and intermediate wheelchair service provision competencies (WHO Basic Level WSTP, 2012 \& Intermediate Level WSTP, 2013). These materials also prepare providers to sit for the Wheelchair Service Provision-Basic Test administered by ISWP (Gartz, 2017). Although this test covers the WHO eight wheelchair delivery steps (i.e. assessment, fitting, follow up; maintenance and repair, prescription, process, production, and user training), it does not include questions that elicit clinical skill. A limitation of ISWP's Basic Wheelchair Service Provider (WSP) certification, which employs the Wheelchair Service Provision-Basic Test, is that it does not yet include a practical or skills assessment. Other certifications are available, such as the Seating and Mobility Specialist, offered by the Rehabilitation Engineering Society of North America (RESNA), which offers credentialing for clinicians who demonstrate competence in seating and mobility (RESNA, 2019). However, it requires knowledge of complex rehabilitation equipment which may not be suitable for those in some low or middle-income countries (LMIC) or volunteers who are assisting with service provision and distribution abroad. Additionally, it also does not include a practical or skills assessment which may provide additional understanding of a provider's wheelchair service competency.

To date, we are unaware of a universal approach for WSP to demonstrate their knowledge and skills to provide wheelchairs at the basic level. A universal remote basic skills assessment that can be accessed across the globe, especially in remote locations where a skilled and experienced provider is not available, is needed. Therefore, the purpose of this study is to develop a remote basic skills assessment approach for WSP. 


\subsection{Specific Aims}

To develop a remote basic skills assessment approach for WSP, this study has the following three specific aims:

1) Develop four mock-client scenarios, including scripts, and corresponding multiple choice and open-ended questions across the WHO eight domains i.e., online quiz (a remote basic skills assessment approach (modality 1$)$ );

2) Develop and validate protocols for two additional remote basic skills assessment approaches for WSP i.e., in-person and video conference assessment skills tests (modalities 2 and 3) and a standard rubric with subject matter experts that can be used for both modalities;

3) Conduct a feasibility study of all three basic skills assessment approaches (modalities 1,2, and 3) with a sample of participants from different contexts.

\subsection{Hypotheses}

1) All three testing approaches are comparable as evidenced by mean Wheelchair Service Provision-Basic Test score (within one standard deviation);

2) All three testing approaches are feasible according to the defined feasibility criteria i.e., participant recruitment, enrollment, and retention (including moderators and test takers), internet access, data collection, perceived benefit, and adherence. 


\subsection{Literature Review}

A review of relevant wheelchair service provision capacity building and assessment literature was conducted to identify approaches to train and test wheelchair service providers. Studies included peer-reviewed research articles and grey literature, published in English between the years 2008 (since the advent of the WHO Guidelines for the Provision of Manual Wheelchairs in Less-Resourced Settings) and 2019 (the year this study was conducted). Research articles that focused on clinical wheelchair service provision process (rather than development or testing of skills to provide wheelchair service) were excluded. A literature search using the following keywords; development AND remote AND assessment AND wheelchair AND skills was performed on the PubMed and Google Scholar databases. The date of the last search was November 30, 2019.

\subsection{Global Capacity Building for Wheelchair Service Providers}

According to the $\mathrm{WHO}$, it is estimated that more than 70 million people in the world require wheelchairs and only $5-15 \%$ of this population have access to one. In an attempt to meet this need in less-resourced settings, people often receive wheelchairs through donations which may be of poor quality and not suitable for both the users and their environment. To further

compound this issue, health workers and some rehabilitation professionals may not be adequately trained to provide appropriate wheelchairs (WHO, 2008). 
To increase the capacity for providing wheelchairs and raise awareness of appropriate products and services, the WHO in partnership with the United States Agency for International Development (USAID) developed the guidelines on the provision of wheelchairs in lessresourced settings (WHO, 2008). The Wheelchair Service Training Packages (WSTP) for basic level, intermediate level and, managers and stakeholders, were built off of the guidelines (WHO, 2012, 2013, 2015). The main purpose of WSTP is to develop skills and knowledge of WSP and to prepare them for wheelchair service delivery (WHO, 2008). In addition, WHO also created the guidelines on the provision of wheelchairs in less-resourced settings and Wheelchair Service Training of Trainers Program (WSTPt) (WHO, 2008, 2017). WSTPt is an effective method to train wheelchair service provision trainers. It has potential to increase the number of trainees and may increase the number of qualified service providers (Munera et al., 2017).

Studies have demonstrated that wheelchairs provided with services by trained providers result in better outcomes. In particular, a study by Toro et al. (2016) concluded that wheelchair service in a less-resourced setting, provided by professionals who followed the WHO 8 steps, increased the users' satisfaction and quality of life compared to those on the waiting list. Similarly, another study revealed that WHO-based wheelchair service program in an LMIC resulted in significant positive changes in all 55 users' satisfaction with regard to the equipment, services and function (Visagie et al., 2016).

As reviewed earlier, a significant body of literature around wheelchair sector capacity building exists, however there is a gap related to WSPs' skills assessment. A study by Fung et al. (2019) investigated the current situation of WSP education in academic rehabilitation programs worldwide. The study aimed to develop an in-depth global description of the WSP education offered in academic rehabilitation programs, the integration process and the associated factors 
i.e., facilitators and barriers. The study findings have informed stakeholders of potential barriers and facilitators to implement adequate WSP education in the curricula of academic rehabilitation programs and therefore have potential to lead to creative strategies to strengthen rehabilitation systems worldwide, through appropriately trained WSP.

In addition, a study developed a wheelchair maintenance training program (WMTP) and questionnaire (WMT-Q) for clinicians and wheelchair users. Training materials including PowerPoint presentations, videos and reference manual, were developed to introduce clinicians to the training program and for use by clinicians to educate wheelchair users (and caregivers when applicable). A remote element of the study was the training and assessment of the recruited clinicians where they were observed by three members of the development team and remotely by an internal expert who had not participated in previous steps. The study revealed that a wheelchair maintenance training program for clinicians and wheelchair users in the USA was practical and well received. Based on results from the questionnaires, it improved clinicians' maintenance knowledge (Toro et al., 2017).

\subsection{Testing Approaches for Rehabilitation Professionals' Knowledge and Skills}

To complement training efforts, there are several testing approaches for rehabilitation professionals' knowledge and skills in the literature. First, related to knowledge tests and certification for WSP specifically, RESNA provides the Assistive Technology Professional (ATP) and Seating and Mobility Specialist (SMS) certifications. It requires knowledge of complex rehabilitation equipment which may not be suitable for those in some LMIC or volunteers who are assisting with service provision and distribution abroad. Additionally, both 
do not include a practical or skills assessment which may provide additional understanding of a provider's wheelchair service competency.

As a potentially more globally relevant alternative, ISWP offers certification and tests for WSP worldwide (WIN, 2019). The certification and tests include basic level WSP certification, intermediate WSP test and trainer recognition process (WIN, 2019). Gartz et al. (2017) developed a basic WSP Test which is now the ISWP Basic Knowledge Test. The development was based on the fact that there was no internationally accepted way to measure the competency of WSP and the test was meant to be a preliminary step towards establishing a certification process. The test consists of 75 multiple-choice questions corresponding to the WHO eight steps to basic wheelchair service provision including assessment, prescription, fitting, production, user training, process and maintenance and repair. The ISWP WSP basic level certificate currently only requires candidates to complete and pass the ISWP Basic Knowledge Tests with at least a score of $70 \%$. The ISWP WSP intermediate level certificate requires candidates to complete a two-step process. First, they are required to complete and pass the ISWP Intermediate Knowledge Test, an online exam with 91 multiple choice questions and 24 demographic questions (pass score of $\geq 70 \%$ ). Second, they should perform a skills test which requires a submission of two case studies (WIN, 2019). Despite this progress, there is still a gap in the literature regarding a basic WSP skills test.

\subsubsection{Remote Skills Test Approaches}

Similarly, the number of studies on remote skills assessment for wheelchair service providers is very limited. The following two studies were identified that utilize a remote approach to assessing skills of WSP. A study by Kirby et al. (2019) investigated the 
effectiveness of remote asynchronous wheelchair skills training for clinicians. Thirty eight physical/occupational therapists and students participated in a self-learning exercise (using online resources and practice in pairs), complemented by periodic expert feedback from a remote expert on wheelchair skills training. The study team concluded that the remote asynchronous method (training followed by assessment) was effective in increasing participants' wheelchairskills capacity and confidence. They emphasized that this model can be further investigated as a delivery method for improving knowledge translation of wheelchair skills training.

A relevant study by Munera et al., (2019) developed an online version of the wheelchair maintenance training program (WMTP) and compared the learning outcomes from the in-person and online programs using the wheelchair maintenance training questionnaire (WMT-Q) before and after training. Twenty-six rehabilitation graduate and undergraduate students participated in the web-based training. The participants submitted videos demonstrating wheelchair maintenance and they were assessed remotely by the project team. This study indicated that there was a similar-increased knowledge for participants between the in-person and online training program, indicating that web-based training may be a viable approach for delivering maintenance training. The study also indicated that remote video submission process was an effective way to evaluate skills related to wheelchair maintenance. Both studies show that a remote training followed by a remote assessment can provide potential approach for assessing WSP skills.

Although the following studies are focused on other rehabilitation professionals' remote testing approaches for skills other than wheelchair service, some elements may be applied to the WSP field. In particular, two studies have revealed remote skills test approaches are feasible. A study by Smith et al. (2019) conducted a feasibility study on a remote video-based assessment 
for clinicians in a global health setting. This pilot study established preliminary inter-rater reliability, validity evidence, and feasibility for an assessment of spinal cord injury (SCI) care providers using simulated patients and remote video capture in community clinic settings. The feasibility indicators included both the technical and logistical challenges. The initial development demonstrated many criteria for validity and some scenarios and tasks demonstrate excellent reliability among raters. They concluded that remote simulation assessment of some skills by clinic-based providers in global health settings is reliable and feasible.

Another study is on the feasibility and reliability of skills assessment using novel virtual environments for paramedics. Cohen et al. (2013) included the technical and non-technical performance as the feasibility indicators. Non-technical performance was generally scored higher than technical performance. The study found that performance assessments were feasible for both experts as well as the participants. The two studies revealed that remote methods are feasible to assess healthcare providers' skills.

In summary, the literature demonstrates that the WHO and other organizations developed open-source training materials to support capacity building of WSP (WHO, 2008, Visagie et al., 2016, Toro et al., 2016, Toro et al., 2017, Munera et al., 2017, and Fung et al., 2019). Several studies suggest increased capacity for WSP after training that employed these materials (Kirby et al., 2019, Munera et al., 2019). Accompanying assessments primarily test providers' knowledge of WSP (e.g.; Toro et al., 2017). However, there is a gap in the literature surrounding assessment of skills of the full wheelchair service provision process (i.e., skills encompassing all 8 of the wheelchair service steps). Remote testing of skills of certain aspects of the WSP process (e.g., in the areas of 'user training' and 'follow-up and maintenance/repairs' (Kirby et al., 2019, Munera 
et al., 2019)) and of other rehabilitation providers' skills (Smith et al., 2019 and Cohen et al., 2013) offer examples of strategies that may be used to test WSP skills. 


\subsection{Design and Methods}

The specific aims of this study include the development and validation of an online skills quiz (modality 1); protocols and a standard rubric for in-person and video conference skills assessment (modalities 2 and 3); and a feasibility study of all three modalities.

\subsection{Specific Aim 1: Development and Validation of Modality 1}

\subsubsection{Content Generation}

In the initial process, the mock-client scenarios, including scripts and corresponding questions for the online quiz (modality 1) were developed based on the WHO 8 steps or domains to basic wheelchair service provision including referral and appointment, assessment, prescription, fitting, production, user training, process (funding and ordering), and maintenance and repair. In the first draft, four mock-client scenarios were created with corresponding multiple-choice and essay questions: a total of 46 multiple-choice (MCQ) and 15 essay questions. Figure 1 summarizes the development process for modality 1 . Both the MCQ and essay questions corresponded to one of the WHO 8-step delivery processes eliciting the test taker's skill in a particular delivery step. 


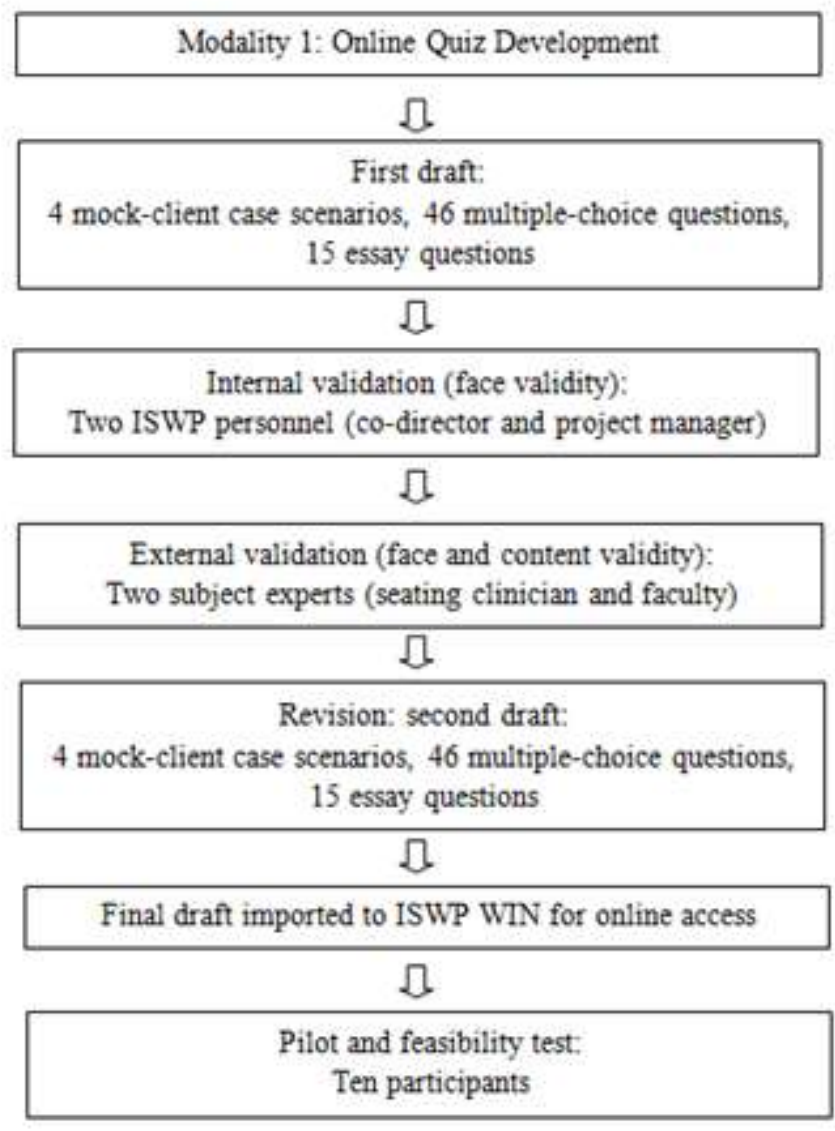

Figure 1 Modality 1 Development Process

\subsubsection{Validation}

Following the development of the first draft, two rounds of review and validation against the WHO 8-step wheelchair delivery process were completed. The first round was an internal review by the ISWP co-director and project manager. The reviewers assessed the face validity of the draft. The second round of review and validation was completed by two external experts from different practice settings (seating clinician and faculty). The external reviewers provided additional face validity assessment and assessed the content validity of the draft. The study team made all materials including the case scripts and question items available via email to experts to 
download with detailed instructions on the order in which to rate and validate them. Experts were given one week to review the materials and communicate via email. Feedback was requested in terms of the item format and content. Each item was rated based on a content validity index with four categories which reflect the characteristics of effective technical communication: relevance, conciseness, clarity, and language (Perelman, Barrett and Paradis, 1996). Each item was scored between 0 and 2 points, for a total of 8 points. Items rated $<6 / 8$ points (less than $75 \%$ ) would be evaluated for revision.

\subsection{Specific Aim 2: Development and Validation of Standard Rubric and Protocols for Modalities 2 and 3}

\subsubsection{Content Generation}

Two protocols and a standard rubric were created for the in-person and video conference skills assessment (modalities 2 and 3 respectively). The standard rubric consisted of testable skills corresponding to the WHO 8-step domains and sub-domains including referral and appointment, assessment, prescription, fitting, production, user training, process (funding and ordering) and maintenance and repair. Each testable skill was given time allocation ranging from 3 to 15 minutes for an estimated maximum of 120 minutes. It was developed with three scoring levels i.e., inadequate skill ( 0 point), emerging skill (1 point) and adequate skill ( 2 point) for each skill for a total of 40 points.

The protocol of modality 2 (in-person test) was created based on the WHO 8-step wheelchair delivery process and then the protocol of modality 3 (video conference test) was 
developed to mirror that of modality 2 . Both protocols included the roles of moderators, model clients and test takers, procedure (including consent procedures - IRB: STUDY19100169) and estimated allocated time of 120 minutes (see Appendices A and B).

\subsubsection{Validation}

Similarly, following the development of the first draft of standard rubric and protocols, two rounds of review and validation were completed. The first round was an internal review by ISWP co-director and project manager. The reviewers assessed the face validity of the draft. The second round of review and validation was completed by two external experts from different practice settings (seating clinician and faculty). The external reviewers provided additional face validity assessment and assessed the content validity of the draft. The study team made all materials including the standard rubric and protocols available via email to experts to download with detailed instructions on the order in which to validate them. Experts were given one week to review the materials and communicate via email.

The standard rubric for testable skills was reviewed and validated against the WHO 8step/domain wheelchair delivery process. Each testable skill was developed to reflect each of the WHO 8 wheelchair delivery process domains. The protocols for modalities 2 and 3 were reviewed and validated with regard to the clarity of the roles (of moderators, model clients and test takers), skills assessment procedure and allocated time. 


\subsection{Specific Aim 3: Feasibility Test}

The literature review suggests a feasibility study is an appropriate method to identify whether remote skills tests are appropriate for particular fields and settings (Cohen, 2013; Smith, 2019). This study therefore aimed to conduct a feasibility study of all skills assessment approaches (modalities 1,2 and 3).

To investigate if this study was feasible, the study goal was to recruit a convenience sample of 10 participants from different national and professional backgrounds. The sample was then divided into two groups: 5 participants for the in-person assessment and 5 for the video conference (modalities 2 and 3). Before participating in either modality 2 or 3 , all participants were asked to complete modality 1 . The inclusion criterion for modality 2 was ISS PreConference attendees who had completed and passed the ISWP Basic Knowledge Test. The inclusion criteria for modality 3 included all participants in the ISWP test database who had completed and passed the ISWP Basic Knowledge Test. A convenience sampling approach was employed for both modalities where a recruitment email was sent to the 35th ISS Pre-Conference attendees list and select test takers from the ISWP test database. 


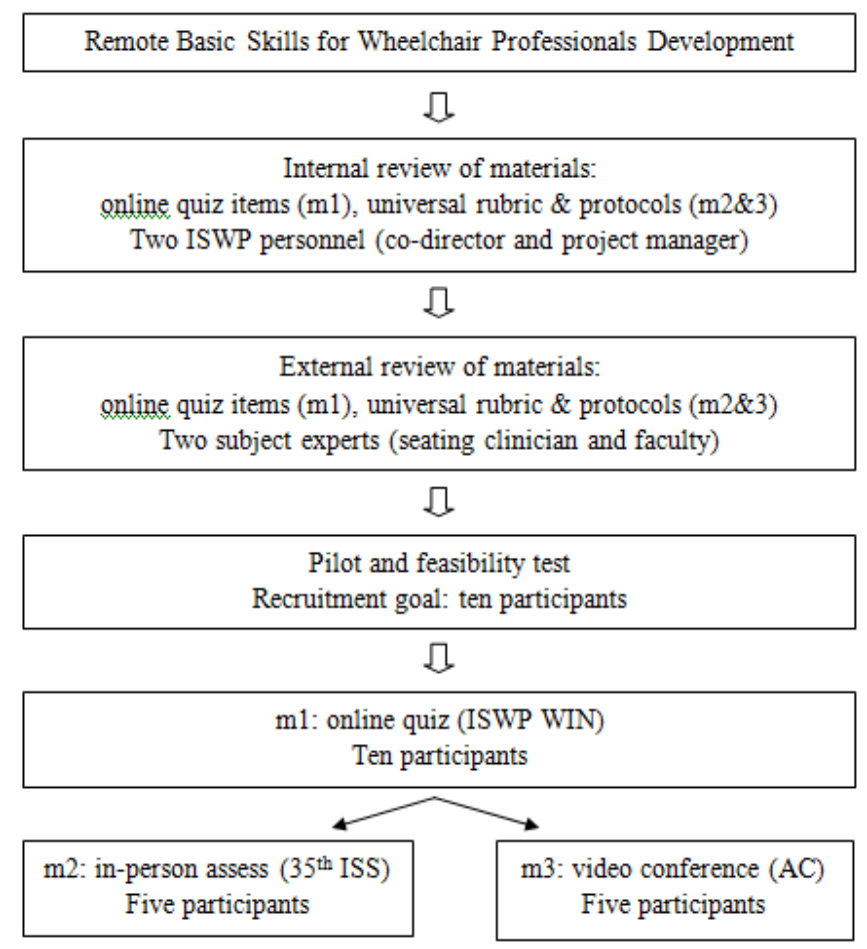

Figure 2 Development and Feasibility Test of All Modalities

All modality 1 items including scenarios and questions were imported to the ISWP Wheelchair International Network (WIN) platform (Figure 3) as a quiz which can be accessed online and is automatically scored, while the standard rubric and protocols for modalities 2 and 3 were finalized in the form of documents (see Appendices A, B and C). The modality 2 component of the feasibility study was conducted at the 35th International Seating Symposium (ISS) Pre-Conference in Pittsburgh from the $18^{\text {th }}$ to $19^{\text {th }}$ of March 2019 (Figure 4). A convenience sampling approach was employed where a recruitment email was sent to the 35 th International Seating Symposium (ISS) Pre-Conference attendees list, as these attendees were already scheduled to be in the area during that time. Modality 3 was hosted on the Adobe Connect videoconference platform (Figure 5). The WHO basic wheelchair delivery steps' forms (see Appendix D) were used for the participants and moderators' reference for both modalities 2 
and 3. The protocols were presented and explained to the participants prior to conducting modalities 2 and 3. Figure 2 summarizes the process from development to feasibility test of all modalities.

Two experts were recruited to moderate modality 2 during the ISS Pre-Conference. The moderator criteria included experts with preferred experience as a trainer (WHO Basic WSTP), familiarity with WHO Basic WSTP and a minimum of 5 years of serving in a WMS role. The mock clients for modality 2 were provided for the participants by the study team while modality 3 participants were responsible for identifying their mock client. Participants, clients, as well as moderators received a reimbursement for their time and participation in the study.

Participants performing either modality 2 or 3 were assessed by the moderators against the standard rubric consisting of WHO 8 steps or domains with a total of 40 points (100\%). There were 20 testable skills represented in the rubric (see Appendix C) and a scale between 0 and 2 (0: inadequate skill, 1: emerging skill and 2: adequate skill). 


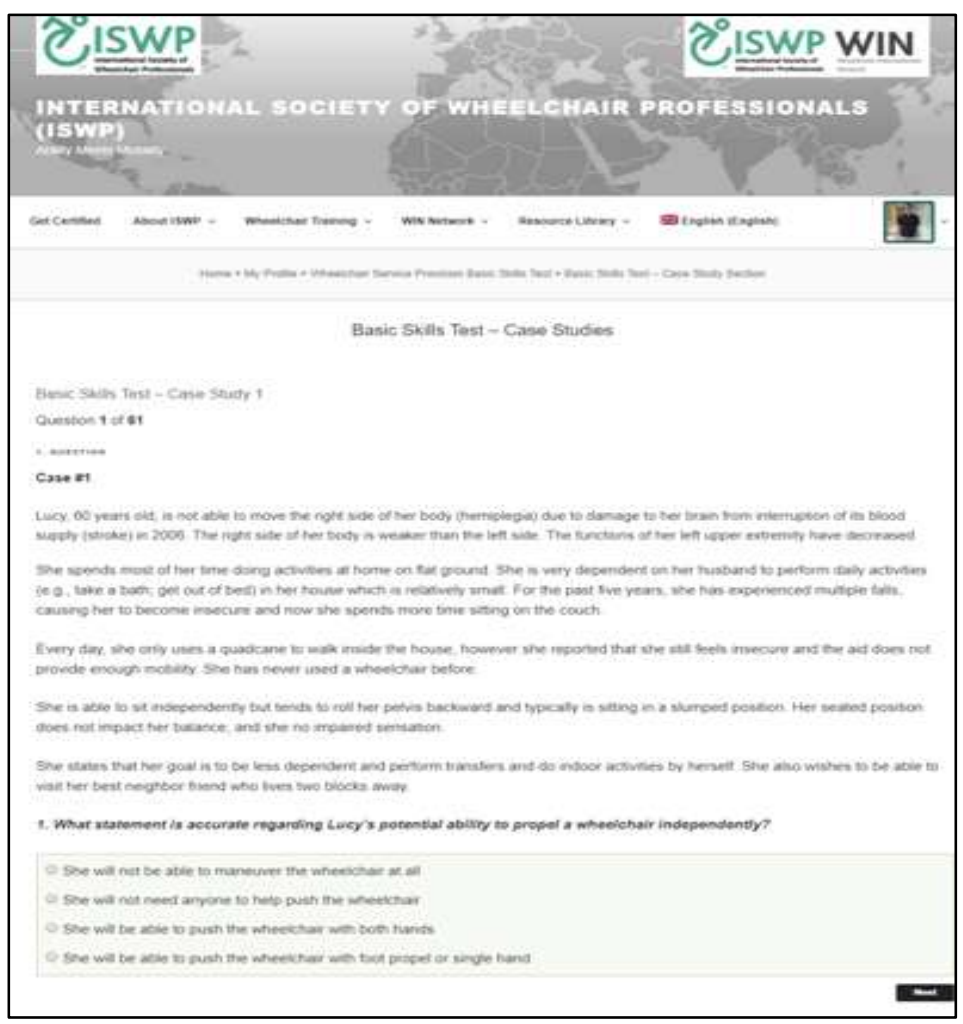

Figure 3 Online Quiz on ISWP WIN

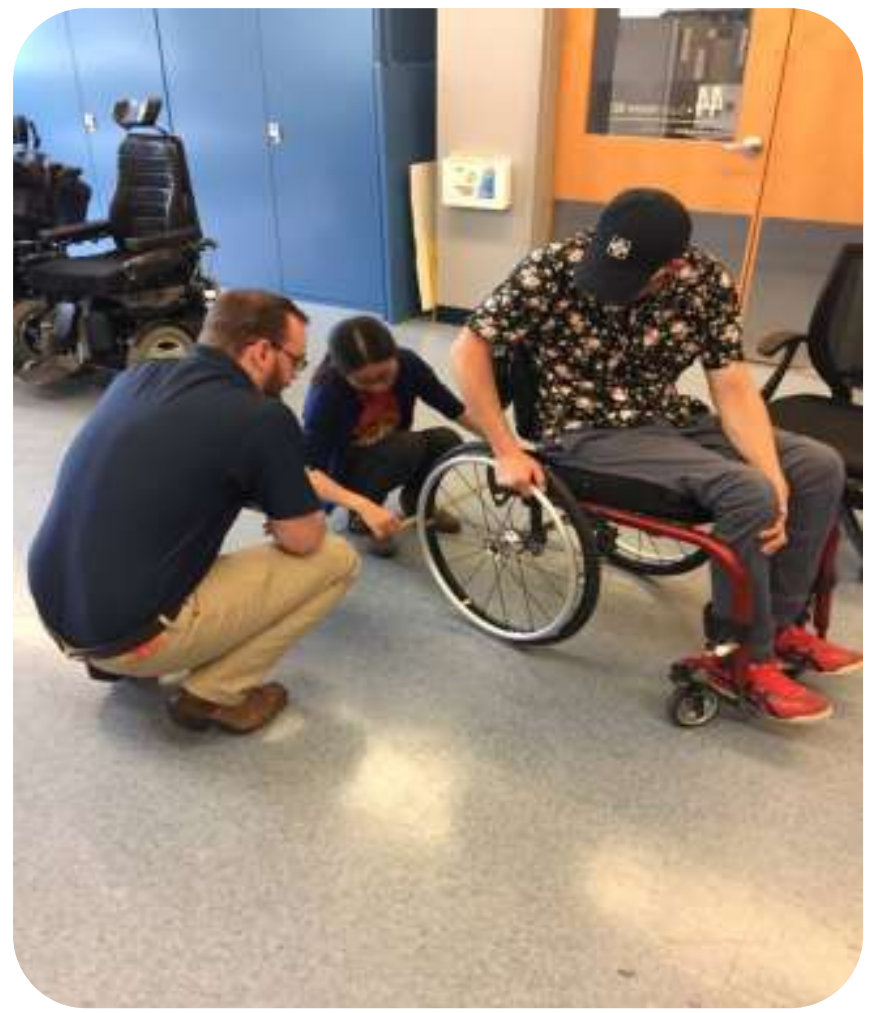

Figure 4 In-Person Assessment during ISS 


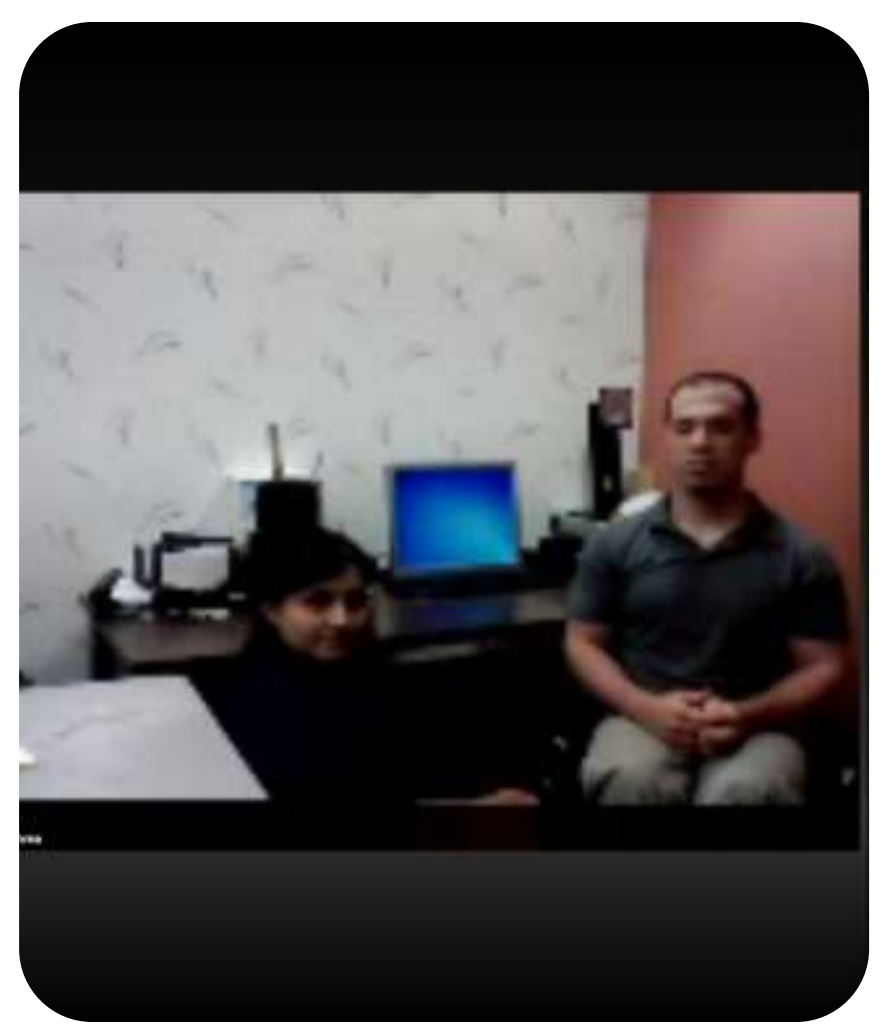

Figure 5 Video Conference on Adobe Connect

After the feasibility study was concluded, we analyzed and compared the mean scores of all three testing approaches to each other and to ISWP Basic Knowledge Test mean score. To further compare the sets of scores and investigate any change in the scores, a non-parametric test, the Wilcoxon signed-rank test was employed with a level of significance ( $\alpha$ : 0.05$)$ using IBM SPSS Statistics v.22. The following Wilcoxon conditions had been met prior to analysis: at least a sample size of 5 pairs, unbiased \& accurate data collection, outcome measures were at least in ordinal scale, data were not approximately normally distributed and were with outliers.

We also looked at the seven feasibility indicators in Table 1: recruitment rate, retention rate, internet access, data collection burden, adherence, study protocol, perceived benefit and satisfaction. 
Table 1 Study Feasibility Indicators

\begin{tabular}{|c|c|c|c|}
\hline Feasibility indicator & Outcome measure & Parameter for success & Feasible \\
\hline $\begin{array}{l}\text { Recruitment rate } \\
\text { - Participants (in-person } \\
\text { and video conference) } \\
\text { - Moderators (in-person and } \\
\text { video conference) }\end{array}$ & $\begin{array}{l}\# \text { of subjects } \\
\text { recruited/protocol }\end{array}$ & \# subjects/protocol & $\mathrm{Y} / \mathrm{N}$ \\
\hline Retention rate & $\begin{array}{l}\% \text { of subjects with } \\
\text { complete data collection } \\
(\mathrm{m} 1 \text { and } \mathrm{m} 2 \text { or } \mathrm{M} 3)\end{array}$ & $\begin{array}{l}\text { Complete } \mathrm{m} 1 \text { and } \mathrm{m} 2 \\
\text { or } \mathrm{m} 3 \text { with } \geq 80 \% \text { of } \\
\text { subjects }\end{array}$ & $\mathrm{Y} / \mathrm{N}$ \\
\hline Internet access & $\begin{array}{l}\text { Recommended } \\
\text { bandwidth }\end{array}$ & $\begin{array}{l}\text { A minimum of } 256 \\
\mathrm{kBps}\end{array}$ & $\mathrm{Y} / \mathrm{N}$ \\
\hline Data collection burden & Test time $\mathrm{m} 1, \mathrm{~m} 2$ or $\mathrm{m} 3$ & $\begin{array}{l}\text { Hours spent for } \mathrm{m} 1 \\
\text { and } \mathrm{m} 2 \text { or } \mathrm{m} 3\end{array}$ & $\mathrm{Y} / \mathrm{N}$ \\
\hline Adherence & Forms validation/grading & $\begin{array}{l}\text { Minimal modifications } \\
\text { are needed }\end{array}$ & $\mathrm{Y} / \mathrm{N}$ \\
\hline Study protocol & Study protocol checklist & $\begin{array}{l}\text { Minimal modifications } \\
\text { are needed }\end{array}$ & $\mathrm{Y} / \mathrm{N}$ \\
\hline $\begin{array}{l}\text { Perceived benefit and } \\
\text { satisfaction }\end{array}$ & $\begin{array}{l}\text { Post-test participant } \\
\text { survey }\end{array}$ & $\begin{array}{l}>90 \% \text { of test takers } \\
\text { agree or strongly agree } \\
\text { that approach is } \\
\text { relevant and has } \\
\text { fidelity to practice }\end{array}$ & $\mathrm{Y} / \mathrm{N}$ \\
\hline
\end{tabular}




\subsection{Results}

\subsection{Validation Results}

\subsubsection{Modality 1}

After the external review of modality 1 was completed, three question items were rated below $75 \%$ i.e., $<6$ points because of low "relevance" rating. The following three items were edited in response to the external reviewers' feedback:

- MCQ 8 of case scenario 1 discussed a short term (wheelchair propulsion) vs. long term recommendation (muscle strengthening) regarding the case. The short term recommendation was more relevant to the case context, therefore the long term recommendation was omitted;

"What follow up recommendation would be likely to have the greatest immediate impact on Lucy? \. Physical therapy and muscle strengthening"

"Which of the following needs to be checked during Lucy's first follow up? A.Whether she can propel as independently as possible"

- MCQ 1 of case scenario 2 included spinal support which was beyond the scope of WSP skills at the basic level, therefore the element regarding the scoliosis support was omitted;

“According to Thomas'prognosis, which of the following likely will be needed?

Đ. Trunk supports"

"E. Additional wheelchair supports" 
- MCQ 11 of case scenario 3 discussed wheelchair measurements. Vocabulary was updated to more commonly used words to describe wheelchair seat depth;

"According to your measurement, what is the correct wheelchair seat length?"

"According to your measurement, what is the correct wheelchair seat depth?"

After final editing, a quiz with four mock-client scenarios followed by a total of $46 \mathrm{MCQ}$ and 15 essay questions were imported to the ISWP online WIN Platform. Table 2 shows the scoring for modality 1 .

Table 2 Modality 1 Scoring

\begin{tabular}{|l|c|c|c|c|}
\hline Case scenario 1 & $13 \mathrm{MCQs}$ & 13 points & 5 essays & 5 points \\
\hline Case scenario 2 & $13 \mathrm{MCQs}$ & 13 points & 5 essays & 4.5 points \\
\hline Case scenario 3 & $13 \mathrm{MCQs}$ & 13 points & 5 essays & 4.5 points \\
\hline Case scenario 4 & $7 \mathrm{MCQs}$ & 7 points & - & - \\
\hline Total MCQs points & \multicolumn{5}{|c|}{60 points } \\
\hline Total essays points & 46 points & 14 points \\
\hline Total possible points & \multicolumn{5}{|c}{} \\
\hline
\end{tabular}

Each MCQ was worth one point for a total possible score of 46 points. Essay questions varied between $.5-1$ points based on the complexity of the question, for a total of 14 possible points.

\subsubsection{Modality 2}

The standard rubric including the testable skills for modality 2 was edited with minor changes against the WHO 8-step wheelchair delivery process and finalized according to the external reviewers' validation and feedback. After the external review, the modality 2 protocol was also finalized in the form of a document consisting of the roles of moderators, model clients and test takers, in-person skills assessment procedure and allocated time breakdown (120 
minutes). There were 20 testable skills within the rubric (see Appendix C) with each scored between 0 and 2 (a total of 40 points (100\%)). The protocol information also reflects the venue of modality 2 skills assessment which was at the ISS Pre-Conference.

\subsubsection{Modality 3}

The same standard rubric was also validated against the WHO 8-step wheelchair delivery service process and finalized for modality 3 . The protocol mirrors modality 2 protocol in the form of document where the participant and client are co-located but the moderator participates from a remote location. It consists of the roles of remote moderators, model clients and test takers, video conference skills assessment procedure and allocated time breakdown (120 minutes). There were 20 testable skills within the rubric (see Appendix C) with each scored between 0 and 2 (a total of 40 points (100\%)). The protocol information reflects the platform on which the skills assessments were hosted, Adobe Connect. 


\subsection{Feasibility Study Results}

\subsubsection{Recruitment}

To meet the study sampling goal, twelve participants were recruited; all completed the modality 1 online quiz and of these 12 , only four were able to take modality 2 assessment during the ISS (Figure 4). Additionally, one local participant completed the test after the ISS. We conducted modality 2 before modality 3 because of the timing of the ISS conference in Pittsburgh and the diversity of the attendees (i.e., modality 3 was not time-sensitive like modality 2 since we did not need to take advantage of an in-person event). The flow of participants is described in Figure 6.

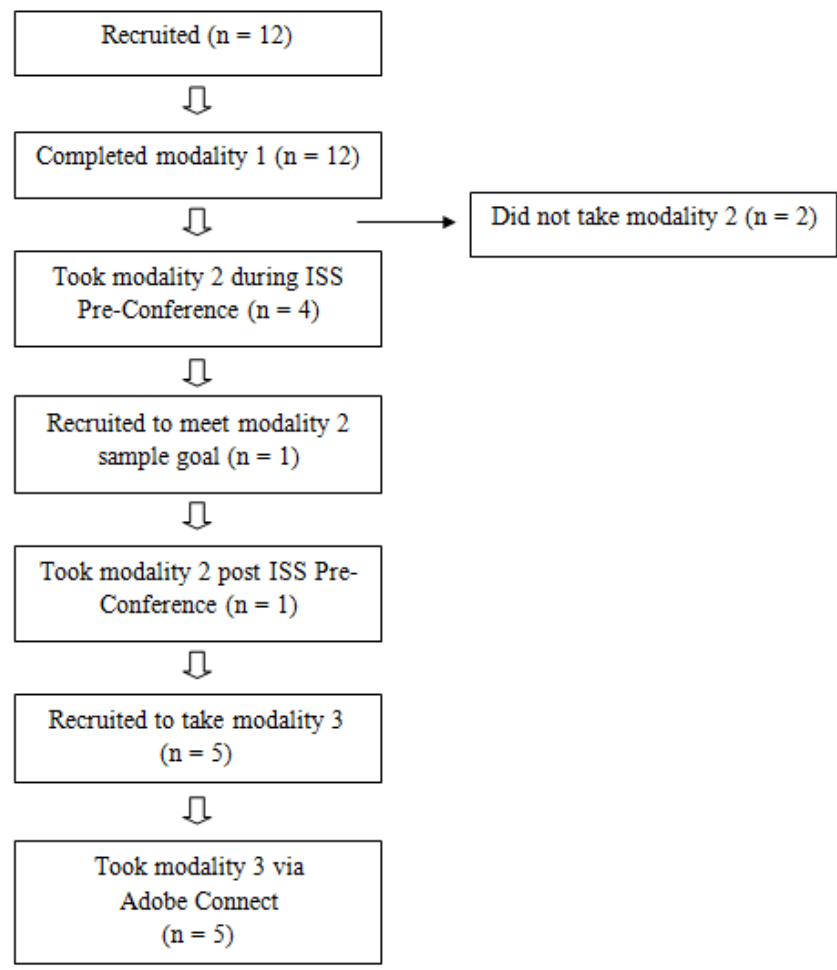

Figure 6 Flow of Participants 
Five participants piloted the modality 3 skills assessment. Participants were recruited using a convenience sampling method through the ISWP distribution list. Table 3 provides sample baseline demographic information.

Table 3 Baseline of Participant Demographics

\begin{tabular}{|c|c|c|c|c|}
\hline Participant & $\begin{array}{c}\text { Country of } \\
\text { Origin }\end{array}$ & Clinical Background & $\begin{array}{c}\text { ISWP Basic } \\
\text { Knowledge Test } \\
\text { Score (\%) }\end{array}$ & $\begin{array}{c}\text { Modalities } \\
\text { (m1 \& m2/ } \\
\text { m1 \& m3) }\end{array}$ \\
\hline 1 & Argentina & Physical Therapist & 75 & $\mathrm{~m} 1$ \& m2 \\
\hline 2 & USA & Occupational Therapist & 81 & $\mathrm{~m} 1$ \& m2 \\
\hline 3 & USA & Physical Therapist & 77 & $\mathrm{~m} 1$ \& m2 \\
\hline 4 & USA & Physical Therapist & 84 & $\mathrm{~m} 1$ \& m2 \\
\hline 5 & Singapore & Occupational Therapist & 75 & $\mathrm{~m} 1$ \& m2 \\
\hline 6 & India & Physical Therapist & 95 & $\mathrm{~m} 1$ \&3 \\
\hline 7 & Indonesia & Prosthetist/Orthotist & 85 & $\mathrm{~m} 1 \& \mathrm{~m} 3$ \\
\hline 8 & Indonesia & Prosthetist/Orthotist & 84 & $\mathrm{~m} 1 \& \mathrm{~m} 3$ \\
\hline 9 & Congo & Physical Therapist & 95 & $\mathrm{~m} 1 \& \mathrm{~m} 3$ \\
\hline 10 & Indonesia & Prosthetist/Orthotist & 84 & $\mathrm{~m} 1$ \\
\hline 11 & USA & Physical Therapist & 77 & $\mathrm{~m} 1$ \\
\hline 12 & USA & Physical Therapist & 83 & \\
\hline
\end{tabular}

For modality 2 moderators, we recruited one occupational therapist (OT) and one physical therapist (PT), who are both specialists in WSP. The OT is both a clinician at the Center for Assistive Technology (CAT) and a faculty member in the University of Pittsburgh Rehabilitation Science and Technology (RST) program. The PT is a PhD student in RST who has clinical and research experience in WSP and also works with ISWP.

We recruited three client models for modality 2 who are manual wheelchair users. They were affiliated with the University of Pittsburgh and Human Engineering Research Laboratories. For modality 3, each participant was responsible for identifying their client model. 


\subsubsection{Feasibility Indicators}

For the feasibility study, we investigated seven indicators across all testing modalities. Success is achieved if approximately $77 \%$ of feasibility indicators are met, based on a prior wheelchair skills' (focusing on the 'user training' step) feasibility study (Best et al., 2018). Accordingly, our success is achieved on 5 of the 7 feasibility indicators. Definitions of the feasibility indicators and parameters for success are defined in Table 1. We hypothesized that all three modalities were feasible according to the following feasibility criteria. As seen in Table 6, we achieved $86 \%$ success or $6 / 7$ feasibility indicators, described below:

1. Recruitment goal: we recruited 12 participants, all of which intended to complete $\mathrm{m} 1,7$ who intended to complete $\mathrm{m} 2$, and 5 who intended to complete $\mathrm{m} 3$. We also recruited 2 moderators for the $\mathrm{m} 2$ tests (one moderator completed 3 tests, one moderator completed 2 tests). Based on these results, we exceeded the recruitment goal for $\mathrm{m} 1$ and $\mathrm{m} 2$.

2. Retention rate: Twelve participants recruited for $\mathrm{m} 1$ completed the protocol (100\% retention rate). Five participants recruited for $\mathrm{m} 2$ completed the protocol, out of a total of 7 (71\% retention rate). Five out of 5 participants recruited for $\mathrm{m} 3$ completed the protocol (100\% retention rate).

3. Internet access: Twelve participants completed modality 1 successfully. The online quiz on WIN platform required a minimum of $256 \mathrm{kBps}$;

4. Data collection burden: The burden of data collection was higher for modality 1 and lower for modality 2 and modality 3 than anticipated (120 min), with mean (SD) testing times of 124 (45) min, 78 (6) min, and 73 (6) min for modality 1, modality 2 and modality 3 respectively (Table 4); 
Table 4 Participant Individual Testing Times

\begin{tabular}{|c|c|c|c|}
\hline Participant & Modality 1 (120 min) & Modality 2 (120 min) & Modality 3 (120 min) \\
\hline 1 & 169 & 85 & \\
\hline 2 & 169 & 80 & \\
\hline 3 & 189 & 80 & \\
\hline 4 & 119 & 75 & 65 \\
\hline 5 & 74 & 70 & 75 \\
\hline 6 & 121 & & 70 \\
\hline 7 & 54 & & 80 \\
\hline 8 & 122 & & 75 \\
\hline 9 & 97 & & 73.00 \\
\hline 10 & 169 & 78.00 & 5.70 \\
\hline Mean & 123.78 & 5.70 & \\
\hline STD & 45.33 & & \\
\hline
\end{tabular}

5. Adherence: A change was made to the validation/grading forms for $\mathrm{m} 1$ items and standard rubric for modality 2 and modality 3 . Minor changes were made after both internal and external review and validation. The changes were primarily regarding low relevance for 3 question items as described in the validation results and whether the rubric testable skills reflected the WHO 8-step wheelchair delivery process (modality 3);

6. Study protocol: A minor change was made to modality 2 and modality 3 protocols after internal and external review and validation. A modification was made to better clarify modality 2 and modality 3 skills assessment procedure;

7. Perceived benefit and satisfaction: Based on the post-test participant survey, $97 \%$ of test takers agreed/strongly agreed that the modality 1 approach was relevant and of reasonable level of difficulty, 100\% agreed that modalities 1 and 3 are of equal difficulty 
but only $40 \%$ agreed that modalities 1 and 2 are of equal difficulty. All test takers agreed/strongly agreed that modalities 1, 2 and 3 have fidelity to practice. See Appendix E for the post-test participant survey.

In addition to relevance, level of difficulty and fidelity to practice, the post-test survey asked for feedback from the participants on which testing formats (ISWP Basic Knowledge Test (pre-requisite), modalities 1, 2 and 3) should be required to demonstrate competency of the basic level wheelchair service provision. Nine out of ten participants $(90 \%)$ responded that all testing formats assessed both knowledge and skills and therefore, should be required to demonstrate competency of the basic level wheelchair service provision.

Table 5 Results of Study Feasibility Indicators

\begin{tabular}{|c|c|c|c|c|}
\hline $\begin{array}{l}\text { Feasibility } \\
\text { indicator }\end{array}$ & $\begin{array}{l}\text { Outcome } \\
\text { measure }\end{array}$ & $\begin{array}{c}\text { Parameter for } \\
\text { success }\end{array}$ & Results & Feasible \\
\hline Recruitment rate & $\begin{array}{l}\text { \# of subjects } \\
\text { recruited/protocol }\end{array}$ & \# subjects/protocol & $\begin{array}{l}5 / 5(\mathrm{~m} 2 \text { protocol }) \\
5 / 5(\mathrm{~m} 3 \text { protocol })\end{array}$ & $\mathrm{Y}$ \\
\hline Retention rate & $\begin{array}{l}\% \text { of subjects with } \\
\text { complete data } \\
\text { collection }(\mathrm{m} 1 \\
\text { AND m2 OR m3) }\end{array}$ & $\begin{array}{l}\text { Complete m1 } \\
\text { AND m } 2 \text { OR m3 } \\
\text { with } \geq 80 \% \text { of } \\
\text { subjects }\end{array}$ & $\begin{array}{l}100 \%(\mathrm{~m} 2) \\
100 \%(\mathrm{~m} 3)\end{array}$ & $\bar{Y}$ \\
\hline Internet access & $\begin{array}{l}\text { Recommended } \\
\text { bandwidth }\end{array}$ & $\begin{array}{l}\text { A minimum of } \\
256 \mathrm{kBps}\end{array}$ & 12/12 completed $\mathrm{m} 1$ & $\mathrm{Y}$ \\
\hline $\begin{array}{l}\text { Data collection } \\
\text { burden }\end{array}$ & $\begin{array}{l}\text { Test time } \mathrm{m} 1, \mathrm{~m} 2 \\
\text { OR m3 }\end{array}$ & $\begin{array}{l}\text { Hours spent for } \\
\text { m1 AND m2 OR } \\
\text { m3 }\end{array}$ & $\begin{array}{c}\mathrm{m} 1: 124(45) \mathrm{min} \\
\mathrm{m} 2: 78(6) \mathrm{min} \\
\mathrm{m} 3: 73(6) \mathrm{min}\end{array}$ & $\mathrm{N}$ \\
\hline Adherence & $\begin{array}{l}\text { Forms } \\
\text { validation/grading }\end{array}$ & $\begin{array}{l}\text { Minimal } \\
\text { modifications are } \\
\text { needed }\end{array}$ & Minimal change & $\mathrm{Y}$ \\
\hline Study protocol & $\begin{array}{l}\text { Study protocol } \\
\text { checklist }\end{array}$ & $\begin{array}{l}\text { Minimal } \\
\text { modifications are } \\
\text { needed }\end{array}$ & Minimal change & $\mathrm{Y}$ \\
\hline $\begin{array}{l}\text { Perceived benefit } \\
\text { and satisfaction }\end{array}$ & $\begin{array}{l}\text { Post-test } \\
\text { participant survey }\end{array}$ & $\begin{array}{l}>90 \% \text { of test } \\
\text { takers agree or } \\
\text { strongly agree that } \\
\text { approach is } \\
\text { relevant and has } \\
\text { fidelity to practice }\end{array}$ & $\begin{array}{l}\text { 97\% agreed/strongly } \\
\text { agreed relevance \& } \\
\text { difficulty level } \\
100 \% \text { agreed/strongly } \\
\text { agreed m1, m2, m3 had } \\
\text { fidelity to practice }\end{array}$ & $\mathrm{Y}$ \\
\hline
\end{tabular}




\subsection{Test Performance}

The total mean score and standard deviation of each modality was compared. We hypothesized that all three modalities (testing approaches) were comparable as evidenced by the mean ISWP Wheelchair Service Provision-Basic Knowledge Test score (within one standard deviation).

Table 6 Mean Score and Standard Deviation Comparison across All Modalities

\begin{tabular}{|c|c|c|c|}
\hline $\begin{array}{c}\text { ISWP Basic Knowledge Test } \\
\text { Score (\%) }\end{array}$ & $\begin{array}{c}\text { Modality 1 } \\
\text { Score (\%) }\end{array}$ & $\begin{array}{c}\text { Modality 2 } \\
\text { Score (\%) }\end{array}$ & $\begin{array}{c}\text { Modality 3 } \\
\text { Score (\%) }\end{array}$ \\
\hline $\mathrm{N}=10$ & $\mathrm{~N}=10$ & $\mathrm{~N}=5$ & $\mathrm{~N}=5$ \\
\hline \multicolumn{3}{|c|}{ Mean (STD) } \\
\hline $83.33(7.09)$ & $75.08(7.53)$ & $91.00(12.45)$ & $84.00(12.82)$ \\
\hline
\end{tabular}

It can be seen that only the total mean score of modality 1 is within one standard deviation compared to that of ISWP Basic Knowledge Test, 7.09 and 7.53 respectively. However, the mean total score of modality 2 is the highest and that of modality 1 is the lowest across all modalities. The total scores of modalities 2 and 3 are within one standard deviation (12.45 and 12.82 respectively), indicating that both modalities are comparable to each other but not to that of the ISWP Knowledge Test.

Table 7 Wilcoxon Signed-Rank Test

\begin{tabular}{|c|c|c|c|}
\hline Test Statistics & M1 and M2 & M2 and M3 & ISWP Basic and M1 \\
\hline Z-score & -1.753 & -1.604 & -1.988 \\
p-value & 0.080 & 0.109 & 0.047 \\
\hline
\end{tabular}

To further compare the sets of individual scores and investigate any change in the scores, we employed a Wilcoxon signed-rank test. As $\alpha$ : 0.05 was used, z-score critical region falls \pm 1.96. Prior to running a Wilcoxon test, a normality test confirmed that our data were not approximately normally distributed (skewed) and possessed a few outliers. A Wilcoxon signed- 
rank test showed that there is no statistical difference between modality 1 and modality 2 scores $(\mathrm{z}>-1.96, \mathrm{p}>0.05)$. Similarly, it showed that there is no statistical difference between modality 2 and modality 3 scores $(\mathrm{z}>-1.96, \mathrm{p}>0.05)$. However, the test results revealed that ISWP Basic Knowledge Test scores were statistically significantly higher than modality 1 scores, indicating that there is statistically significant difference between ISWP Basic Knowledge Test and modality 1 scores. This is in contrast with our test performance results.

The following graphs compare the individual participant scores across three modalities; modalities 1 and 2 and modalities 1 and 3:

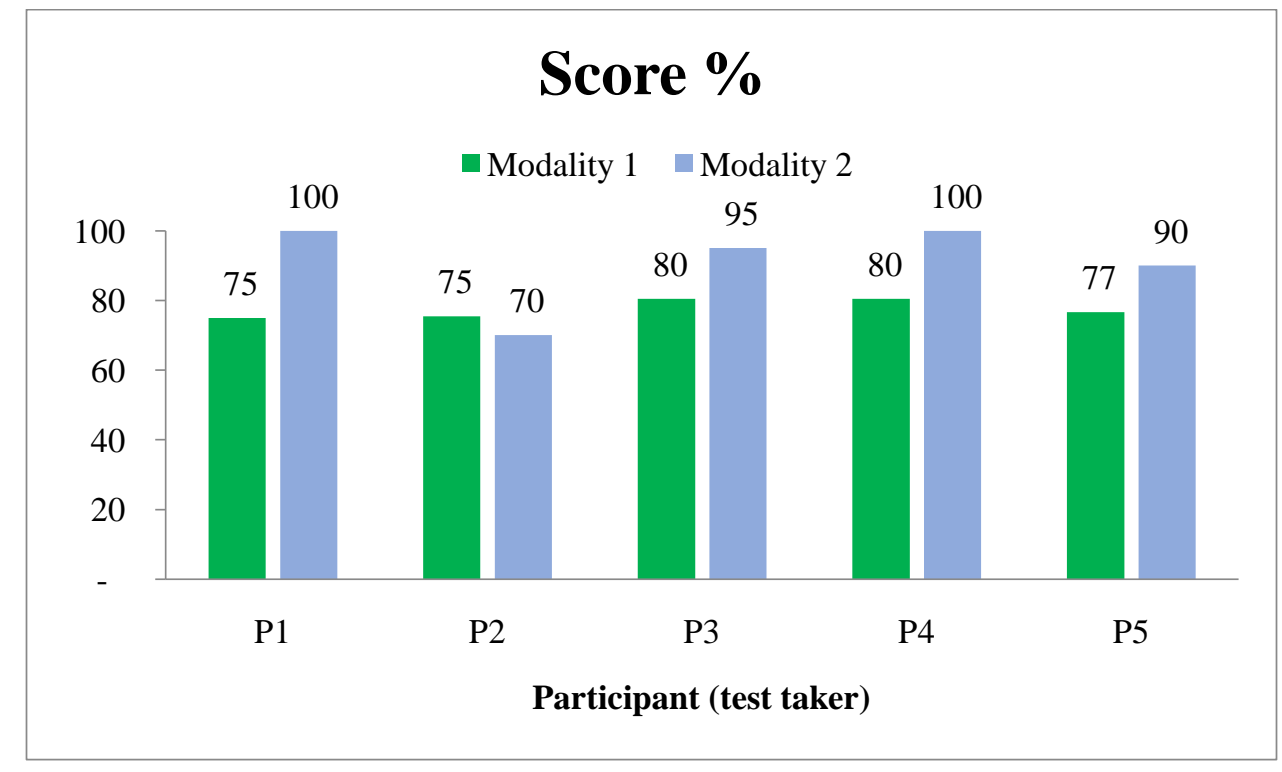

Figure 7 Modalities 1 and 2 Individual Score Comparison

Figure 7 shows that all 5 modality 2 individual scores are higher than those of modality 1 except one participant. Four out of 5 participants scored higher in modality 3 than modality 1, as seen in Figure 8. 


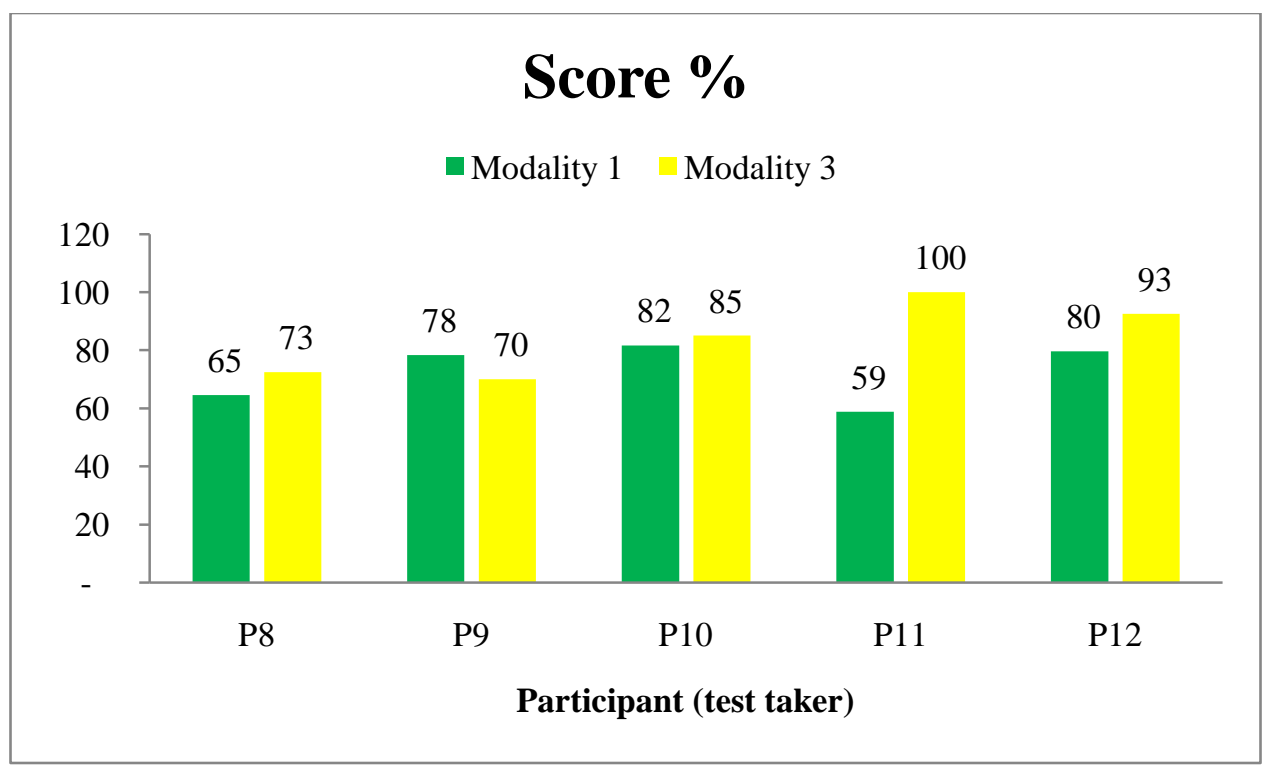

Figure 8 Modalities 1 and 3 Individual Score Comparison 


\subsection{Discussion}

\subsection{Three Modalities Have Potential to Serve as a Universal Skills Test}

In hypothesis 1 , we hypothesized that all three modalities were comparable as evidenced by the mean ISWP Basic Knowledge Test score (within one standard deviation). However, the results show that only the total mean score of modality 1 is within one standard deviation $(\mathrm{SD}=$ .44) compared to that of ISWP Basic Knowledge Test and therefore we rejected our first hypothesis. The comparability between modality 1 and ISWP Basic Knowledge Test might be due to their similar testing format which is an online quiz. The mean total score of modality 2 is

the highest suggesting participants score higher on the in-person skills assessment than ISWP Knowledge Test and modality 1 . This may be due to the presence of a client model, allowing the participant to demonstrate their skills synchronously. The primary advantage of the presence of a client model for both modalities 2 and 3 is that it allows clarifications between the client, participant and moderator, leaving less opportunity for misunderstanding.

The total mean score of modality 3 is higher than that of modality 1 suggesting that participants score higher on the skills assessment with the presence of a client model. Similar to modality 2 , the presence of client models in modality 3 can potentially improve participants' skills performance because they perform hands-on assessment on the client models. On the other hand, participants tend to score lower in modality 1. It might be due to the format of MCQ which is difficult to elicit skills and based on these results, we are not confident if modality 1 reflects WSP basic skills. Therefore, modalities 2 and 3 may provide more fidelity to practice than modality 1 . The scoring for modalities 2 and 3 may have also been too liberal, in other words, 
making it easier to score a higher score based on the scoring rubric than modality 1 . In modality 1 , the answer is either right or wrong. In both modalities 2 and 3, partial credit can be provided on each item. The total scores of modalities 2 and 3 are within one standard deviation (.37), indicating that both modalities will be comparable to each other. It shows that people score as well on the video conference (modality 3 ) as they do on the in-person skills (modality 2), suggesting these approaches may have similar fidelity to practice.

The Wilcoxon signed-rank test results show that there is no statistically significant difference between modality 2 and modality 3 scores as well as modality 2 and modality 1 scores, suggesting all three approaches may have similar fidelity to practice. We chose modality 2 as the control (gold standard approach to measuring skills) in comparison to the other two modalities because it shows the highest potential. The test results, however, indicate that ISWP Basic Knowledge Test scores are statistically significantly different than modality 1 scores, which is in contrast with our test performance results. Although their testing format is similar, knowledge and skills scoring format may be different and unique enough that they are measuring different domains. We are not confident with our first hypothesis, whether a knowledge test is correlated to a skills test.

The feasibility study results show that we achieved $>77 \%$ success. According to Best et al., 2018, this parameter suggests that the majority of the feasibility indicators are met and that all three modalities are feasible. Reflecting on these results, our second hypothesis was not rejected and we can conclude that all three modalities are feasible as indicated by recruitment rate, retention rate, internet access, data collection burden, adherence, study protocol and perceived benefit and satisfaction. The study team experienced difficulty recruiting participants for modality 3 and participants reported difficulty recruiting their client model due to their 
availability. Since we recruited participants from countries outside the US, different time zones also contributed to the difficulty experienced during modality 3 . One recommendation to improve modality 3 would be for the professional organization facilitating the test (e.g. ISWP) to provide recommendations for whom modality 3 test is appropriate. Although all remote modalities are provided for any WSP with basic skills, for modality 3 specifically, ISWP could recommend this approach only for those who work in outpatient clinics or similar format (e.g., research setting with access to clients) to minimize logistical challenges.

Several studies (Kirby et al., 2019, Munera et al., 2019, Smith et al., 2019, and Cohen et al., 2013) offered examples of remote skills testing strategies for WSP and other rehabilitation providers. They concluded that a remote testing format is reliable and feasible to assess WSP and other rehabilitation care providers' skills. The findings of our feasibility study reveal that all three modalities are feasible to serve as a remote skills assessment approach for basic WSP and therefore support the results of the other studies.

\subsection{Potential Barriers and Facilitators of Testing Modalities}

Although all three modalities were developed as a remote universal assessment for basiclevel WSP globally, some potential barriers have been identified across three modalities including cost and human resources. First, modality 1 is an online quiz on the ISWP WIN platform which requires internet access (i.e. bandwidth). Some basic WSP living in certain rural areas of LMIC may find it difficult to access internet. Modality 2 was designed to take place in a seating and mobility conference where many potential and interested WSP are present. However, many basic-level WSP reside in LMIC and work at different clinical settings where financial 
support is challenging and therefore expenses associated with accommodation and travel to a conference can be a barrier.

Second, human resources can also be another barrier. Moderators and client models are recruited in modality 2 and it can be challenging. Modality 3 poses a challenge for basic-level WSP because internet access and human resources are required to perform the skills assessment. While modality 1 requires minimal bandwidth, significant bandwidth may be required for modality 3 as video is more reliant on a strong connection than web platform. Another barrier for an implementing organization may be that they do not have financial resources available to provide reimbursements to the people involved in the skills assessment including participants, clients and moderators.

There were also some issues with administering the modalities related to language. For example, one of our modality 3 participants does not speak English fluently so we needed a translator participating in the skills assessment test. As we did not go through a formal translation of the test, some components of the skills assessment could be lost in the translation. This example might be a barrier although that particular participant scored very high because of her prominent knowledge on the basic-level wheelchair service skills. However, we believe what we gained in terms of having someone from an additional country/context participate was worth this minor limitation (i.e. generalizability).

A study by Munera et al., 2019 compared the learning outcomes from an in-person and online program using the WMT-Q before and after training, in which participants submitted videos demonstrating wheelchair maintenance and they were scored by remote evaluators. The study found a similar-increased knowledge between the training formats, indicating that an online approach may be viable for a skills training. This is a modality format which we did not 
test but could be an alternative. However, potential challenges could include internet access to submit the videos and also human resources regarding the remote evaluators.

One potential facilitator and testing alternative could be if the test were to occur immediately following basic-level wheelchair training (e.g., m1 and/or m2), some logistics, costs and human resources required could be reduced. Additional facilitators may include using translated study materials including modality cases and question items, both protocols and WHO forms. The documents would need to be translated formally using forward/backward translation. Forward-translations and back-translations is a well-established method to achieve different language versions of the English instrument that are conceptually equivalent in each of the target countries/cultures (WHO, 2019). We can therefore avoid issues of documentation related to language barrier. In addition, if a particular participant does not communicate in English well (e.g. the example above), a bilingual moderator should be recruited.

\subsection{Limitations}

Our study poses some limitations. In terms of study design and methods, first, the sampling method employed was convenience sampling which resulted in self-selection bias during recruitment. Second, our sample size is relatively small and therefore limits the generalizability of the results. For the feasibility study, our study was designed to allow each participant to only experience 2 out of 3 modalities (either modality 1 followed by modality 2 or modality 1 followed by modality 3) due to limited human resources and timeframe.

There was a 6-month time lag between the two approaches, modalities 2 and 3, because we experienced difficulty recruiting participants for modality 3. The participants reported that it 
was difficult identifying a client model, although one out of five participants chose modality 3 as the only testing format that assesses basic-level WSP competency.

Additionally, when the participants recruited their client models, it might have inserted some form of bias, potentially on either side. For example, the client models for modality 2 who we recruited likely have a high level of WMS knowledge which could have inadvertently been shared with the test taker. Similarly, the client models recruited by modality 3 participants may also have had 'off-line' convos with the client models in advance that could have polluted their responses either favorably or unfavorably.

\subsection{Future Work}

In the future, we aim to expand this work by conducting an additional validation and reliability study for all modalities. We also plan on conducting trials to expand across other settings, and potentially providing translation to other languages than English to reach a greater

number of test takers across the globe, and parallel the ISWP Basic Knowledge Test language options (i.e. Arabic, Albanian, English, French, Hindi, Khmer, Lao, Mandarin, Romanian, Russian, Portuguese, Spanish, Urdu and Vietnamese).

Simulation which has been a trend in assessment of health professional skills could be an alternative method of approach. However, in our context, access to technology and cost to develop such a test may be infeasible. This may also be issues for our target population based on our feasibility criteria in this study.

An asynchronous modality approach where participants submit a skills video and then the video is scored remotely by an evaluator can also be developed as an option. In their studies, 
Kirby et al., 2019 and Munera et al., 2019 show that remote trainings can provide potential approach for assessing WSP skills. With predicted challenges including internet access and human resources, we could develop a protocol which will minimize the challenges. 


\subsection{Conclusion}

In summary, this study aimed to develop, validate and conduct a feasibility study of three skills assessment modalities: online quiz modality 1, in-person skills assessment modality 2 and video conference skills assessment modality 3 . The results show that the total mean scores of all modalities are not equal. Only the total mean score of modality 1 is comparable to that of ISWP Basic Knowledge Test (within one standard deviation) and therefore we rejected our first hypothesis. The total mean score of modality 1 was the lowest implying that modalities 2 and 3 better represent WSP basic skills in real practice. However, the Wilcoxon signed-rank test reveals that no statistically significant difference between modalities 2 and 3 scores as well as modalities 2 and 1 scores. The ISWP Basic Knowledge Test scores are instead statistically significantly higher than modality 1 scores. While ISWP Basic Knowledge Test and modality 1 scores are within one standard deviation in response to our first hypothesis, we are not confident that these two tests are comparable as they measure different domains. Some additional studies need to be conducted to ensure that all three modalities are of equal level of difficulty.

The feasibility study results reveal that all three modalities are feasible ( $>77 \%$ success) to serve as a remote skills assessment approach for basic WSP. The success was achieved by the majority of the feasibility indicators (6/7) and therefore our second hypothesis was not rejected. Modalities 1, 2 and 3 have potential to serve as a remote assessment through ISWP or other credentialing organizations to identify whether a WSP possesses basic level skill.

We would recommend ISWP to develop specific recommendations for whom modality 3 is suitable, including those WSP working in outpatient clinics to minimize the logistical 
challenges. We believe that modality 3 skills assessment approach can provide benefits and serve as a remote skills assessment for basic WSP where experienced trainers may not reside.

Considering the logistical challenges experienced and the results of the study, modality 2 shows promising results and the highest potential to be included in the WSP basic skills certification process and is therefore recommended by the study team. 


\section{Appendix A Modality 1 Sample}

Instructions: Please complete the External Reviewer Scoring sheet for each scenario. Additionally, please feel free to mark up this document directly with your proposed edits or additions.

Text key: black (vignettes, questions and multiple choices), red (correct answers) and blue (WHO WSTP Basic testable skills)

\section{Case \#1}

Lucy, 60 years old, is not able to move the right side of her body (hemiplegia) due to damage to her brain from interruption of its blood supply (stroke) in 2006. The right side of her body is weaker than the left side. The functions of her left upper extremity have decreased since then. No deformity is found.

She spends most of her time doing activities at home on flat ground. She is very dependent on her husband to perform daily activities (e.g., take a bath; get out of bed) in her house which is relatively small. For the past five years, she has experienced multiple falls, causing her to become insecure and now she spends more time sitting on the couch.

Every day, she only uses a quadcane to walk inside the house, however she reported that she still feels insecure and the aid does not provide enough mobility. She has never used a wheelchair before.

She is able to sit independently but tends to roll her pelvis backward and typically is sitting in a slumped position. Her seated position does not impact her balance, and she no impaired sensation.

She states that her goal is to be less dependent and perform transfers and do indoor activities by herself. She also wishes to be able to visit her best neighbor friend who lives two blocks away.

\section{MCQ}

1. What statement is accurate regarding Lucy's potential ability to propel a wheelchair independently? (user training: condition, wheelchair skills)

a. She will not be able to maneuver the wheelchair at all

b. She will not need anyone to help push the wheelchair

c. She will be able to push the wheelchair with both hands

d. She will be able to push the wheelchair with foot propel or single hand

2. According to the case, what is the best answer for why Lucy needs a wheelchair? (assessment: information)

a. She can walk but only for a short distance and wants to function as independently as possible

b. She can walk for long distances and complete indoor activities by herself

c. She is a very active person

d. She cannot walk at all

3. The figure to the right illustrates how Lucy looks in her comfortable seated position. With regard to the pelvis, what posture do you see when she is sitting and what implication does this present? (assessment: posture) 
a. Trunk is bending backward and it can avoid pressure sores and fixed deformities

b. Trunk is bending forward and it can affect breathing and digestion

c. Trunk is bending backward and it can make swallowing harder

d. Trunk is twisted and it can relieve discomfort or pain

4. Where will Lucy most likely use the wheelchair and what implication does this have for your prescription? (assessment: lifestyle and environment)

a. In the community; activities for a long travel distance

b. In the market; outdoor activities for a long travel distance

c. At home; indoor activities for a short travel distance

d. In an office; indoor activities for a short travel distance

5. Why does a wheelchair with footrests which are removable and can be swung away benefit Lucy? (prescription: type and features)

a. Because this would prevent her from propelling with her foot

b. Because she can do a standing transfer

c. Because this would enable her to propel better

d. Because this would enable her to reach the push rim

6. How do you conclude that Lucy has good support system at home? (assessment: support system)

a. She has a lot of children

b. She is engaged in a wheelchair community

c. Her husband helps her perform daily activities

d. She has very good insurance for her healthcare

7. Which of the following affects how Lucy pushes a wheelchair? (assessment: functional ability)
a. Strength of trunk muscles
b. Strength and control of arms
c. Insecurity due to falls
d. Insecurity due to the transition from quadcane to wheelchair

8. Which of the following needs to be checked during Lucy's first follow up? (follow up: follow up)

a. Whether she can propel as independently as possible

b. Whether she can visit her neighbor friend

c. Whether she increases her body weight

d. Whether she spends less time sitting inside the house

9. According to this case, who do you train in transfer methods? (user training: wheelchair skills)

a. Both Lucy and husband so that they can support each other

b. Only Lucy's husband, as she cannot transfer independently 
c. Both Lucy and husband because the only caregiver is the husband

d. Only Lucy, as her husband may not be a consistent caregiver

10. Lucy wishes to transfer from a manual wheelchair to another surface. What is the most appropriate technique to use? (user training: wheelchair skills)
a. Standing pivot transfer
b. Seat to floor transfer
c. Forwards transfer
d. Two-person lift

11. What type of cushion should be prescribed for Lucy with regard to her sensation and pressure relief techniques? (prescription: cushion)
a. Pressure relief cushion
b. Comfort cushion
c. Foam cushion
d. No cushion needed

12. What type of wheelchair should you recommend for her? (prescription: type and features)

a. A lightweight wheelchair with arm supports and a full back support

b. A lightweight wheelchair with no arm supports and back support

c. A standard folding wheelchair with a supportive seat

d. A standard folding wheelchair with a short back support

13. Which of the following should be considered for the prescribed wheelchair in terms of Lucy's mobility and transfers at home? (prescription: type and features)
a. Wide wheelbase and removable armrests
b. Short wheelbase and removable armrests
c. Low back support and low footrests
d. Low back support and fixed footrests

\section{Open-ended}

1. What problems can occur when Lucy is sitting in a slumped position (not sitting upright)? (assessment: physical, posture)

2. What do you consider during user training for Lucy who has never had a wheelchair? (user training: wheelchair skills)

3. What would be the ideal prescribed wheelchair? (prescription: size and adjustments)

4. Do you have any consideration for the wheel base and features in terms of her mobility and transfers at home? (prescription: type and features)

5. When would you recommend follow up, and what recommendations would you have for her? (follow up: follow up) 


\section{Appendix B Modality 2 Protocol}

\section{THE IN-PERSON APPROACH GUIDELINES AND PROTOCOL}

- Roles

○ Moderators:

1. Appointed moderators will grade each testable skill and step performed by test takers using the standard rubric.

2. You may need to come closer to the test taker if accuracy of a process is very important.

○ Mock clients:

1. Wheelchair user models will act according to their true physical and physiological condition. Therefore, all data provided by the client will remain confidential. Both the test taker and moderator will verbally consent to keeping all responses confidential.

- Test takers:

1. Test takers will perform the eight WHO Basic Domains and the corresponding testable skills according to the client model(s) assigned to them

2. WHO Wheelchair Service Training Basic Level forms (Wheelchair Assessment and Prescription forms) will be provided

3. When performing the skills and steps, test takers will also simultaneously provide verbal explanation to moderators when performing observations and equipment checks. 
4. Please assume that this is a new case, in other words the mock client is a primary wheelchair user. Therefore the client requires instructions for every step.

5. With regard to the prescription step, even if you agree with the current wheelchair, you need to elaborate why you do so.

6. Please make sure that every step you are performing is documented.

- Room setup

- The assessment will take place in a quiet and clean private room during the International Seating Symposium (ISS) pre-conference period (March 18-19, 2019).

- Schedule and time allocation

○ It will take approximately 2 hours (120 minutes) with the following breakdown:

\begin{tabular}{|c|c|}
\hline WHO WTP Domains & Time (minutes) \\
\hline Assessment & 30 \\
\hline Fitting & 15 \\
\hline Prescription (selection) & 15 \\
\hline Process & - \\
\hline Product preparation & 25 \\
\hline User training & 30 \\
\hline Follow up & 5 \\
\hline
\end{tabular}

- Grading

- Every testable skill and step with regard to each domain will be evaluated by moderator on the standard rubric and responses will be recorded on the test 
taker's answer sheet and WHO Wheelchair Service Training Basic Level forms (Assessment \& Prescription). The completed answer sheet and WHO forms will be available for the moderator's reference after the test. 


\section{Appendix C Modality 3 Protocol}

\section{THE VIDEO CONFERENCE APPROACH GUIDELINES AND PROTOCOL}

Thank you for your interest in participating in our study as a test taker. You will be asked to complete three steps:

Step 1: pass the ISWP Wheelchair Service Provision Basic Knowledge Test

Step 2: complete the online mock-client case scenarios quiz

Step 3: Video conference assessment. Prior to it, you will need to recruit your model client who meets the inclusion criteria below. Your skills assessment will be conducted in the form of video conference via Adobe Connect platform. A camera will be needed for the video conference. Adobe Connect instructions file is attached separately.

- Roles

○ Moderators:

1. Appointed moderators will grade each testable skill and step performed by test takers using the standard rubric.

○ Model clients:

1. For the purpose of this assessment, the client inclusion criteria include wheelchair users who are active and do not require postural support.

2. Wheelchair user models will act according to their true physical and physiological condition. Therefore, all data provided by the client will remain confidential. Both the test taker and the moderator will verbally consent to keep all responses confidential.

○ Test takers: 
1. Test takers will perform the eight steps for appropriate wheelchair provision recommended by the World Health Organization (WHO) and the corresponding testable skills according to the client model(s) identified.

2. WHO Wheelchair Service Training Basic Level Assessment and Prescription forms will be provided upon the scheduling of the video conference.

3. When performing the wheelchair provision steps, test takers will simultaneously provide verbal explanation to the moderators.

4. Please assume that this is a new case, in other words, the model client is a primary wheelchair user. Therefore, the client requires instructions for every step.

5. With regard to the prescription step, even if you agree with the current wheelchair, you need to elaborate on why you do so.

6. Please make sure that every step you are performing is documented.

7. You are responsible for finding your model client who meets the inclusion criteria (see above).

8. Because it will be done remotely via Adobe Connect, please make sure that when performing your assessment, you and your client can be seen clearly by the moderator.

- Video Conference setup

○ The assessment will take place remotely via Adobe Connect.

- Make sure that you have a good camera and a microphone/voice input device. It does not need to be a laptop camera - it could be an external webcam. 
- Prior to your scheduled assessment, please try to test out your camera and microphone. Please refer to the attached Adobe Connect Instructions.

- Schedule and time allocation

○ It will take approximately 2 hours (120 minutes) with the following breakdown:

\begin{tabular}{|c|c|}
\hline WHO WTP Domains & Time (minutes) \\
\hline Assessment & 30 \\
\hline Fitting & 15 \\
\hline Prescription (selection) & 15 \\
\hline Process & - \\
\hline Product preparation & 25 \\
\hline User training & 30 \\
\hline Follow up & 5 \\
\hline
\end{tabular}

- Grading

○ Every testable skill and step with regard to each domain will be evaluated by moderator on the standard rubric and responses will be recorded on the test taker's answer sheet and WHO Wheelchair Service Training Basic Level forms (Assessment \& Prescription). The completed answer sheet and WHO forms will be available for the moderator's reference after the test. 
Appendix D Standard Rubric

\begin{tabular}{|c|c|c|c|c|c|}
\hline Domain & Testable skill & Inadequate skill (0) & Emerging skill (1) & Adequate skill (2) & Time allocation \\
\hline \multirow{3}{*}{ Assessment } & $\begin{array}{l}\text { Able to ask questions about } \\
\text { what ADL/IADLs the client } \\
\text { wants to accomplish } \\
\text { Able to write the client relevant } \\
\text { goals }\end{array}$ & $\begin{array}{l}\text { Does not ask any } \\
\text { questions about } \\
\text { ADL/IADLS or asks } \\
\text { irrelevant questions to } \\
\text { ADL/IADLS }\end{array}$ & $\begin{array}{l}\text { Asks 3-5 questions } \\
\text { relevant to } \\
\text { ADL/IADLS and } \\
\text { some follow up } \\
\text { questions (when } \\
\text { warranted) }\end{array}$ & $\begin{array}{l}\text { Asks } 5 \text { or more } \\
\text { questions relevant to } \\
\text { ADL/IADLS and } \\
\text { many follow up } \\
\text { questions (when } \\
\text { warranted) }\end{array}$ & $5 \min$ \\
\hline & $\begin{array}{l}\text { Able to conduct interview } \\
\text { with the client to obtain } \\
\text { relevant information e.g. } \\
\square \text { physical condition } \\
\square \text { posture } \\
\square \text { lifestyle and environment } \\
\square \text { existing wheelchair } \\
\square \text { presence, risk or history } \\
\text { of pressure sores } \\
\square \text { method of pushing } \\
\square \text { personal objectives } \\
\text { (goals) }\end{array}$ & $\begin{array}{l}\text { Does not ask any } \\
\text { questions about } \\
\text { relevant information } \\
\text { as listed }\end{array}$ & $\begin{array}{l}\text { Asks 3-5 questions } \\
\text { about relevant } \\
\text { information as listed }\end{array}$ & $\begin{array}{l}\text { Asks the majority of } \\
7 \text { questions about } \\
\text { relevant information } \\
\text { as listed }\end{array}$ & $10 \mathrm{~min}$ \\
\hline & \begin{tabular}{|l} 
Able to perform \\
necessary (basic) measurements \\
$\begin{aligned} \square & \text { hip width } \\
\square & \text { seat depth } \\
\square & \text { calf length } \\
\square & \text { backrest height } \\
& \text { seat width }\end{aligned}$
\end{tabular} & $\begin{array}{l}\text { Places measurement } \\
\text { tool improperly and } \\
\text { performs less than } \\
\text { half of all } \\
\text { measurements }\end{array}$ & $\begin{array}{l}\text { Places measurement } \\
\text { tool properly and } \\
\text { performs at least half } \\
\text { of all measurements }\end{array}$ & $\begin{array}{l}\text { Places measurement } \\
\text { tool properly and } \\
\text { performs the majority } \\
\text { of } 11 \text { measurements }\end{array}$ & $15 \mathrm{~min}$ \\
\hline
\end{tabular}




\begin{tabular}{|c|c|c|c|c|c|}
\hline & $\begin{array}{ll}\square & \text { seat depth } \\
\square & \text { seat height } \\
\square & \text { backrest height } \\
\square & \text { footrest height } \\
\square & \text { frame length } \\
\square & \text { wheelbase }\end{array}$ & & & & \\
\hline & $\begin{array}{l}\text { Able to observe the } \\
\text { client push the wheelchair }\end{array}$ & $\begin{array}{l}\text { Does not observe the } \\
\text { client push the } \\
\text { wheelchair }\end{array}$ & $\begin{array}{l}\text { Observes the client } \\
\text { push the wheelchair } \\
\text { but cannot explain } \\
\text { what s/he observes }\end{array}$ & $\begin{array}{l}\text { Observes the client } \\
\text { push the wheelchair } \\
\text { and can explain what } \\
\text { s/he observes }\end{array}$ & \\
\hline & $\begin{array}{l}\text { Able to observe the client do } \\
\text { transfers }\end{array}$ & $\begin{array}{l}\text { Does not observe the } \\
\text { client do transfers }\end{array}$ & $\begin{array}{l}\text { Observes the client do } \\
\text { transfers but cannot } \\
\text { explain what s/he } \\
\text { observes (techniques) }\end{array}$ & $\begin{array}{l}\text { Observes the client do } \\
\text { transfers and can } \\
\text { explain what s/he } \\
\text { observes (techniques) }\end{array}$ & \\
\hline $\begin{array}{c}\text { Prescription } \\
\text { (selection) }\end{array}$ & $\begin{array}{l}\text { Able to perform specific check } \\
\text { on the wheelchair before fitting } \\
\text { i.e. } \\
\square \quad \text { wheelchair frame } \\
\square \quad \text { castor and rear wheels } \\
\square \text { footrests } \\
\square \quad \text { armrests } \\
\square \text { backrest height } \\
\square \quad \text { rear wheels position } \\
\text { support and comfort }\end{array}$ & $\begin{array}{l}\text { Does not perform } \\
\text { specific fitting checks } \\
\text { as listed }\end{array}$ & $\begin{array}{l}\text { Performs half (3-4) of } \\
\text { specific fitting checks } \\
\text { as listed }\end{array}$ & $\begin{array}{l}\text { Performs the majority } \\
\text { of specific fitting } \\
\text { checks as listed }\end{array}$ & $12 \mathrm{~min}$ \\
\hline & $\begin{array}{l}\text { Able to describe the most } \\
\text { suitable cushion for the client }\end{array}$ & $\begin{array}{l}\text { Cannot describe the } \\
\text { most suitable cushion }\end{array}$ & $\begin{array}{l}\text { Can describe the most } \\
\text { suitable cushion } \\
\text { without any } \\
\text { suggestion }\end{array}$ & $\begin{array}{l}\text { Can describe the most } \\
\text { suitable cushion by } \\
\text { suggesting off-the- } \\
\text { shelf or customized } \\
\text { cushion }\end{array}$ & $3 \mathrm{~min}$ \\
\hline Fitting & Able to observe the client & Does not observe the & Observes the client sit & Observes the client sit & $6 \mathrm{~min}$ \\
\hline
\end{tabular}




\begin{tabular}{|c|c|c|c|c|c|}
\hline & $\begin{array}{l}\text { sit from front/back and side } \\
\text { view }\end{array}$ & $\begin{array}{l}\text { client sit from } \\
\text { front/back and side } \\
\text { view }\end{array}$ & $\begin{array}{l}\text { from front/back and } \\
\text { side view but cannot } \\
\text { explain what s/he } \\
\text { observes }\end{array}$ & $\begin{array}{l}\text { from front/back and } \\
\text { side view and can } \\
\text { explain what s/he } \\
\text { observes }\end{array}$ & \\
\hline & $\begin{array}{l}\text { Able to check pressure under } \\
\text { the client's seat bones and to } \\
\text { test if the cushion works }\end{array}$ & $\begin{array}{l}\text { Does not check } \\
\text { pressure }\end{array}$ & $\begin{array}{l}\text { Checks pressure } \\
\text { incorrectly - without } \\
\text { explanation to the } \\
\text { client }\end{array}$ & $\begin{array}{l}\text { Checks pressure } \\
\text { correctly by placing } \\
\text { his/her fingertips } \\
\text { under the client's seat } \\
\text { bones, ask the client } \\
\text { to sit back down on } \\
\text { his/her fingers and } \\
\text { then identify how } \\
\text { much his/her } \\
\text { fingertips can wriggle } \\
\text { and explains the test } \\
\text { to the client }\end{array}$ & $4 \mathrm{~min}$ \\
\hline & $\begin{array}{l}\text { Able to do fitting of } \\
\text { individual client. The } \\
\text { fitting checks include: } \\
\square \quad \text { wheelchair size and } \\
\text { adjustments } \\
\square \text { posture } \\
\square \text { fit while the client is } \\
\text { moving }\end{array}$ & $\begin{array}{l}\text { Does not perform } \\
\text { fitting checks as listed }\end{array}$ & $\begin{array}{l}\text { Performs half (2) of } \\
\text { dfitting checks as listed }\end{array}$ & $\begin{array}{l}\text { Performs the majority } \\
\text { of fitting checks as } \\
\text { listed }\end{array}$ & $5 \mathrm{~min}$ \\
\hline Procosc & Able to document processes & $\begin{array}{l}\text { Does not do any } \\
\text { documentation }\end{array}$ & $\begin{array}{l}\text { Does inadequate } \\
\text { documentation }\end{array}$ & $\begin{array}{l}\text { Does adequate } \\
\text { documentation }\end{array}$ & - \\
\hline Process & $\begin{array}{l}\text { Able to follow the WHO } \\
\text { guidelines step by step, and not } \\
\text { miss any step }\end{array}$ & $\begin{array}{l}\text { Does not follow the } \\
\text { guidelines }\end{array}$ & $\begin{array}{l}\text { Follows the } \\
\text { guidelines but not } \\
\text { orderly }\end{array}$ & $\begin{array}{l}\text { Follow the guidelines } \\
\text { orderly }\end{array}$ & - \\
\hline & $\begin{array}{l}\text { Able to show professionalism, } \\
\text { build rapport to the client and } \\
\text { work with a client-centered }\end{array}$ & $\begin{array}{l}\text { Does not show } \\
\text { professionalism, does } \\
\text { not build rapport and }\end{array}$ & $\begin{array}{l}\text { Shows some } \\
\text { professionalism, } \\
\text { builds rapport and }\end{array}$ & $\begin{array}{l}\text { Shows } \\
\text { professionalism and } \\
\text { respect, builds rapport }\end{array}$ & - \\
\hline
\end{tabular}




\begin{tabular}{|c|c|c|c|c|c|}
\hline & approach & $\begin{array}{l}\text { show client-centered } \\
\text { approach }\end{array}$ & $\begin{array}{l}\text { shows some client- } \\
\text { centered approach }\end{array}$ & $\begin{array}{l}\text { and shows client- } \\
\text { centered approach }\end{array}$ & \\
\hline \multirow{3}{*}{$\begin{array}{c}\text { Product } \\
\text { preparation }\end{array}$} & $\begin{array}{l}\text { Able to assemble and adjust } \\
\text { parts of the wheelchair: } \\
\square \text { height of backrest, } \\
\text { armrests, footrests and } \\
\text { push handles } \\
\square \text { position of rear wheels } \\
\text { and brakes }\end{array}$ & $\begin{array}{l}\text { Does not show ability } \\
\text { to do assembly or } \\
\text { adjustment }\end{array}$ & $\begin{array}{l}\text { Shows ability to do } \\
\text { assembly or } \\
\text { adjustment some of } \\
\text { the wheelchair parts } \\
\text { as listed }\end{array}$ & $\begin{array}{l}\text { Shows ability to do } \\
\text { assembly or } \\
\text { adjustment the } \\
\text { majority of the } \\
\text { wheelchair parts as } \\
\text { listed }\end{array}$ & $10 \mathrm{~min}$ \\
\hline & \begin{tabular}{|l} 
Able to check if the wheelchair \\
is safe and ready to \\
use including: \\
$\square \quad$ no sharp edges \\
$\square \quad$ no parts are damaged or \\
scratched \\
$\square$ the wheelchair travels in a \\
straight line \\
$\square$ front castor wheels \\
$\square$ front castor barrels \\
$\square$ rear wheels \\
$\square$ brakes \\
$\square$ footrests \\
$\square$ frames
\end{tabular} & $\begin{array}{l}\text { Does not check for } \\
\text { safety at all }\end{array}$ & $\begin{array}{l}\text { Checks half (4-5) of } \\
\text { the safety items as } \\
\text { listed }\end{array}$ & $\begin{array}{l}\text { Checks the majority } \\
\text { of the safety items as } \\
\text { listed }\end{array}$ & $12 \mathrm{~min}$ \\
\hline & \begin{tabular}{|l} 
Able to check cushion \\
$\square \quad$ correct cover \\
$\square \quad$ during sitting, tight but \\
not too tight \\
$\square \quad$ fully covers the seat
\end{tabular} & $\begin{array}{l}\text { Does not check } \\
\text { cushion }\end{array}$ & $\begin{array}{l}\text { Checks cushion by } \\
\text { considering some (1- } \\
\text { 2) of the items as } \\
\text { listed }\end{array}$ & $\begin{array}{l}\text { Checks cushion by } \\
\text { considering the } \\
\text { majority of the items } \\
\text { as listed }\end{array}$ & $3 \mathrm{~min}$ \\
\hline
\end{tabular}




\begin{tabular}{|c|c|c|c|c|c|}
\hline \multirow{3}{*}{$\begin{array}{c}\text { User } \\
\text { training }\end{array}$} & $\begin{array}{l}\text { Able to train basic level } \\
\text { wheelchair mobility skills e.g. } \\
\square \quad \text { pushing } \\
\square \quad \text { turning } \\
\square \quad \text { going up and down slopes } \\
\square \text { going up and down stairs } \\
\text { with assistance } \\
\square \text { partial wheelie } \\
\text { with safety }\end{array}$ & $\begin{array}{l}\text { Does not demonstrate } \\
\text { basic level wheelchail } \\
\text { mobility skills with } \\
\text { safety }\end{array}$ & $\begin{array}{l}\text { Demonstrates } 2-3 \\
\text { ir basic level wheelchaiı } \\
\text { mobility skills as } \\
\text { listed with safety }\end{array}$ & $\begin{array}{l}\text { Demonstrates the } \\
\text { rmajority of basic } \\
\text { level wheelchair } \\
\text { mobility skills as } \\
\text { listed with safety }\end{array}$ & $15 \mathrm{~min}$ \\
\hline & \begin{tabular}{|c} 
Able to train the following: \\
$\square \quad$ independent transfer from \\
wheelchair to bed \\
$\square$ assisted transfer with a \\
transfer board from \\
wheelchair to bed \\
$\square$ \\
assisted standing transfer \\
from bed to wheelchair \\
$\square$ \\
independent transfer from \\
wheelchair to floor \\
$\quad$ independent transfer from \\
floor to wheelchair
\end{tabular} & $\begin{array}{l}\text { Does not demonstrate } \\
\text { ability to train any } \\
\text { transfer skill }\end{array}$ & $\begin{array}{l}\text { Demonstrates } 2-3 \\
\text { transfer skills as listec }\end{array}$ & $\begin{array}{l}\text { Demonstrates the } \\
\text { dmajority of transfer } \\
\text { skills as listed }\end{array}$ & $10 \mathrm{~min}$ \\
\hline & $\begin{array}{l}\text { Able to solve common fitting } \\
\text { problems including: } \\
\square \quad \text { seat depth too short or too } \\
\text { long } \\
\square \quad \text { footrests height too low or } \\
\text { too high } \\
\square \quad \text { legs tend to roll inwards } \\
\text { or outwards } \\
\square \quad \text { wheelchair is too wide } \\
\square \quad \text { feet tend to slide off the }\end{array}$ & $\begin{array}{l}\text { Does not demonstrate } \\
\text { ability to solve } \\
\text { common fitting } \\
\text { problems }\end{array}$ & $\begin{array}{l}\text { Demonstrates ability } \\
\text { to solve } 2-3 \text { common } \\
\text { fitting problems as } \\
\text { listed }\end{array}$ & $\begin{array}{l}\text { Demonstrates ability } \\
\text { to solve the majority } \\
\text { of common fitting } \\
\text { problems as listed }\end{array}$ & $5 \mathrm{~min}$ \\
\hline
\end{tabular}




\begin{tabular}{|c|c|c|c|c|c|}
\hline & footrests & & & & \\
\hline Follow-up & $\begin{array}{l}\text { Able to explain how to care for } \\
\text { wheelchair and cushion at } \\
\text { home including: } \\
\square \quad \text { clean the wheelchair and } \\
\quad \text { cushion } \\
\square \quad \text { oil moving parts } \\
\square \quad \text { pump up tires } \\
\square \quad \text { tighten nuts and bolts } \\
\square \quad \text { tighten spokes } \\
\square \quad \text { check the cushion }\end{array}$ & $\begin{array}{l}\text { Does not explain care } \\
\text { for wheelchair and } \\
\text { cushion }\end{array}$ & $\begin{array}{l}\text { Explains care for } \\
\text { wheelchair and } \\
\text { cushion by explaining } \\
3 \text { of the items as } \\
\text { listed }\end{array}$ & $\begin{array}{l}\text { Explains care for } \\
\text { wheelchair and } \\
\text { cushion by explaining } \\
\text { the majority of the } \\
\text { items as listed }\end{array}$ & $5 \mathrm{~min}$ \\
\hline
\end{tabular}




\section{Appendix E WHO Forms}

\section{WHEELCHAIR ASSESSMENT FORM}

For assessment of wheelchair users who can sit upright easily. Wheelchair users who cannot sit upright easily may need assessment by a person with 'intermediate' level training. Keep this form in the wheelchair user's file.

Assessor's name: Date of assessment:

\section{1: Interview Assessment}

\section{Information about the wheelchair user}

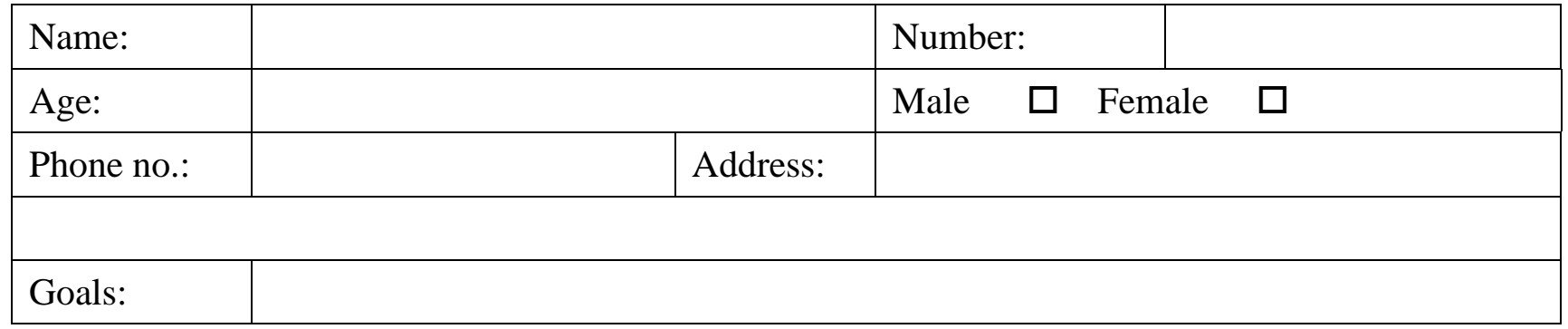

\section{Physical condition}

Cerebral palsy $\square$ Polio $\square$ Spinal cord injury $\square$ Stroke $\square$

Frail $\square$ Spasms or uncontrolled movements $\square$

Amputation: R above knee $\square$ R below knee $\square \mathrm{L}$ above knee $\square$ L below knee

Bladder problems $\square$ Bowel problems

If the wheelchair user has bladder or bowel problems, is this managed? Yes $\square$ No

Others:

\section{Lifestyle and environment}

Describe where the wheelchair user will use their wheelchair:

Distance travelled per day: Up to $1 \mathrm{~km} \square \quad 1-5 \mathrm{~km} \square$ More than $5 \mathrm{~km} \square$ Hours per day using wheelchair? Less than $1 \square \quad$ 1-3 $\square \quad 3-5 \square \quad$ 5-8 $\square>8$ hours $\square$ When out of the wheelchair, where does the user sit or lie down and how (posture and the surface?

Transfer: Independent $\square$ Assisted $\square$ Standing $\square$ Non Standing $\square$ Lifted $\square$ Other 
Type of toilet (if transferring to a toilet): Squat $\square$ Western $\square$ Adapted $\square$

Does the wheelchair user often use public/private transport? Yes $\square$ No

If yes, then what kind: Car $\square$ Taxi $\square$ Bus $\square$ Other

\section{Existing wheelchair (if a person already has a wheelchair)}

Does the wheelchair meet the user's needs?Yes $\square$ No

Does the wheelchair meet the user's environmental conditions?Yes $\square$ No

Does the wheelchair provide proper fit and postural support? Yes $\square$ No

Is the wheelchair safe and durable?(Consider whether there is a cushion)Yes $\square$ No

Does the cushion provide proper pressure relief (if user has pressure sore risk)? Yes $\square$ No

Comments:

If yes to all questions, the user may not need a new wheelchair. If no to any of these questions, the user needs a different wheelchair or cushion; or the existing wheelchair or cushion needs repair or modifications.

\section{2: Physical Assessment}

\section{Presence, risk of or history of pressure sores}

$/ / /=$ does not feel $\mathrm{O}=$ previous pressure sore

- = existing pressure sore
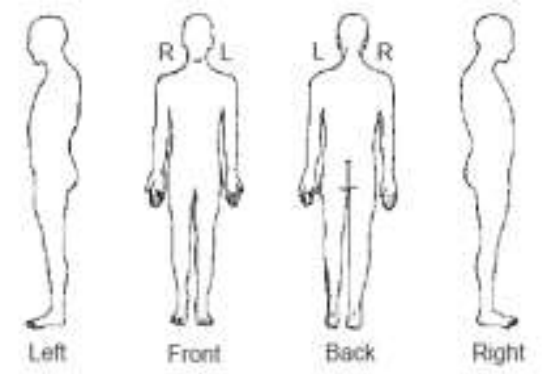

\begin{tabular}{|l|c|c|c|c|}
\hline Can feel normally? & Yes & $\square$ & No & $\square$ \\
\hline Previous pressure sore? & Yes & $\square$ & No & $\square$ \\
\hline Current pressure sore? & Yes & $\square$ & No & $\square$ \\
\hline $\begin{array}{l}\text { If yes, is it an open sore } \\
\text { (stage 1 -4)? }\end{array}$ & Yes & $\square$ & No & $\square$ \\
\hline
\end{tabular}

Duration and cause:

Is this person at risk* of a pressure sore? *A person who cannot feel or has 3 or more risk factors is at risk. Risk factors: cannot move, moisture, poor posture, previous / current pressure sore, poor diet, ageing, under or over weight.

\section{Method of pushing}

How will the wheelchair user push their wheelchair? Both arms $\square$ Left arm $\square$ Right arm Both legs $\square$ Left leg $\square$ Right leg $\square$ Pushed by a helper 
Comment:

\section{Measurements}

\begin{tabular}{|c|c|c|c|c|c|}
\hline & \multicolumn{2}{|c|}{ Body Measurement } & $\begin{array}{l}\text { Measurement } \\
(\mathbf{m m})\end{array}$ & $\begin{array}{l}\text { Change body measurement to ideal } \\
\text { wheelchair size }\end{array}$ & $\begin{array}{l}\text { Wheelchair } \\
\text { measurement }\end{array}$ \\
\hline A & \multicolumn{2}{|l|}{ Hip width } & & Hip width $=$ seat width & \\
\hline \multirow[t]{2}{*}{ B } & \multirow[t]{2}{*}{ Seat depth } & $\mathrm{L}$ & & \multirow{2}{*}{$\begin{array}{l}\text { B less } 30-50 \mathrm{~mm}=\text { seat depth } \\
\text { (if length is different, use shorter } \\
\text { one) }\end{array}$} & \\
\hline & & $\mathrm{R}$ & & & \\
\hline \multirow[t]{2}{*}{$\mathrm{C}$} & \multirow[t]{2}{*}{ Calf length } & $\mathrm{L}$ & & \multirow{2}{*}{$\begin{array}{l}=\text { top of seat cushion* to footrests } \\
\text { height } \text { or } \\
=\text { top of seat cushion* to floor for } \\
\text { foot propelling }\end{array}$} & \\
\hline & & $\mathrm{R}$ & & & \\
\hline $\mathrm{D}$ & \multicolumn{2}{|c|}{$\begin{array}{l}\text { Bottom of rib } \\
\text { cage }\end{array}$} & & \multirow{2}{*}{$\begin{array}{l}\text { = top of seat cushion* to top of } \\
\text { backrest } \\
\text { (measure D or E - depending on the } \\
\text { user's need) }\end{array}$} & \\
\hline $\mathrm{E}$ & \multicolumn{2}{|c|}{$\begin{array}{l}\text { Bottom of } \\
\text { shoulder blade }\end{array}$} & & & \\
\hline
\end{tabular}

*check the height of the cushion that the wheelchair user will use. 


\section{WHEELCHAIR PRESCRIPTION (SELECTION) FORM}

This prescription (selection) form is for recording the choice of wheelchair, wheelchair components and cushion for a wheelchair user who is able to sit upright comfortably.

\section{Wheelchair user information}

\begin{tabular}{|l|l|l|l|}
\hline Wheelchair user's name: & & Number: & \\
\hline Date of assessment: & & Date of fitting: & \\
\hline Assessor's name: & & & \\
\cline { 1 - 2 }
\end{tabular}

\section{Type of wheelchair and size selected}

To select the type of a wheelchair:

○ Discuss with the wheelchair user;

o Think about the most important needs of the wheelchair user;

○ Check: wheelchair frame, castor and rear wheels, footrests, armrests, backrest height (or adjustability), rear wheels position, support and comfort.

\begin{tabular}{|l|l|l|}
\hline Type of wheelchair & & Size \\
\hline & $\square$ & \\
\hline & $\square$ & \\
\hline & $\square$ & \\
\hline & $\square$ & \\
\hline & $\square$ & \\
\hline
\end{tabular}

\section{Type of cushion selected}

\begin{tabular}{|l|l|l|}
\hline Type of cushion & & Size \\
\hline Eg. Foam pressure relief cushion & $\square$ & \\
\hline Eg. Flat foam cushion & $\square$ & \\
\hline & $\square$ & \\
\hline
\end{tabular}

\section{Agreed}

\begin{tabular}{|l|l|}
\hline Signature of the user: & \\
\hline Signature of the assessor: & \\
\hline Signature of the moderator: & \\
\hline
\end{tabular}




\section{Is the wheelchair ready?}

Has the wheelchair been checked to make sure it is safe to use and all parts are working?

\section{Check size and adjustments}

Seat width:
Should fit closely.
$\begin{aligned} & \text { Footrests height: } \\ & \text { The thighs are fully supported on the cushion with no gaps. The feet } \\ & \text { are fully supported on the footrests with no gaps. } \\ & \text { ofween the back } \\ & \text { of the knee and the } \\ & \text { seat /cushion. }\end{aligned}$
Backrest height:
The wheelchair user has the support they need and freedom to move
their shoulders to push (if self propelling).
The wheelchair user's arm should be in line with the rear axle when
Wanging down.
be at a right angle.


Seat height (for foot propelling):

With the wheelchair user sitting upright, the back should be comfortably supported by the backrest, with feet resting flat on the floor.

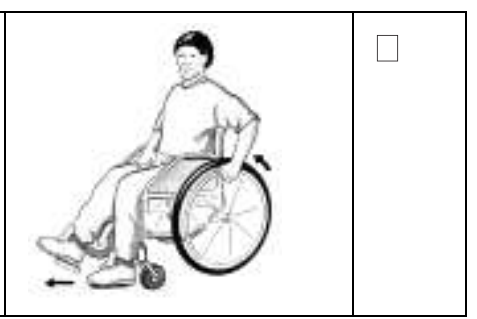

\section{Check posture}

Is the wheelchair user able to sit upright comfortably?

Check posture from the side.

Check posture from front /back. 


\section{Check pressure}

Check pressure under seat bones for all wheelchair users at risk of developing a pressure sore.

\begin{tabular}{ll|l|} 
Ask wheelchair user to lean forward or push up. \\
Place fingertips under wheelchair user's seat bone.
\end{tabular}

\section{Check fit while the wheelchair is moving}

Does the backrest allow the wheelchair user freedom to move their shoulders to push?

Does the backrest give the wheelchair user enough support?

Do the wheelchair user's feet stay on the footrests?

Is the rear wheels position correct for the user?

\section{Action?}

Is there any further action necessary? Write any actions in the wheelchair user's file. 


\begin{tabular}{|c|c|}
\hline \multicolumn{2}{|l|}{ Whole wheelchair } \\
\hline There are no sharp edges & $\square$ \\
\hline No parts are damaged or scratched & $\square$ \\
\hline The wheelchair travels in a straight line & $\square$ \\
\hline \multicolumn{2}{|l|}{ Front castor wheels } \\
\hline Spin freely & $\square$ \\
\hline Spin without touching the fork & $\square$ \\
\hline Bolts are tight & $\square$ \\
\hline \multicolumn{2}{|l|}{ Front castor barrels } \\
\hline Castor fork spins freely & $\square$ \\
\hline \multicolumn{2}{|l|}{ Rear wheels } \\
\hline Spin freely & $\square$ \\
\hline Axle bolts are tight & $\square$ \\
\hline Tyres inflated correctly (with thumb pressure, wheel can be depressed less than $5 \mathrm{~mm}$ ) & $\square$ \\
\hline Push rims are secure & $\square$ \\
\hline \multicolumn{2}{|l|}{ Brakes } \\
\hline Function properly & $\square$ \\
\hline \multicolumn{2}{|l|}{ Footrests } \\
\hline Footrests are securely attached & $\square$ \\
\hline \multicolumn{2}{|l|}{ Frame } \\
\hline For a folding wheelchair - the wheelchair folds and unfolds easily & $\square$ \\
\hline For a wheelchair with fold down backrest - the backrest folds and unfolds easily & $\square$ \\
\hline \multicolumn{2}{|l|}{ Cushion } \\
\hline The cushion is in the cover correctly & $\square$ \\
\hline
\end{tabular}




\begin{tabular}{|l|l|}
\hline The cushion is sitting on the wheelchair correctly & $\square$ \\
\hline The cushion cover fabric is tight but not too tight & $\square$ \\
\hline If the wheelchair has a solid seat: the cushion fully covers the solid seat & $\square$ \\
\hline
\end{tabular}




\section{WHEELCHAIR FOLLOW UP FORM}

This form is for recording information before a follow up visit.

\begin{tabular}{|l|l|}
\hline Wheelchair and Cushion Care (How To) & $\square$ \\
\hline Clean the wheelchair and cushion & $\square$ \\
\hline Oil the wheelchair parts & $\square$ \\
\hline Pump up tires & $\square$ \\
\hline Tighten nuts and bolts & $\square$ \\
\hline Tighten spokes and/or axle & $\square$ \\
\hline Check the cushion & \\
\hline
\end{tabular}




\section{Appendix F Participant Survey}

\section{QUESTIONNAIRE}

The intent of this survey is to elicit your feedback on our Paralyzed Veterans of America (PVA)-supported "Development of a Remote Basic Skills Assessment" project. This goal of this project was to develop and pilot a remote basic skills assessment for wheelchair service providers to demonstrate they are qualified to provide wheelchairs at the basic level.

Please circle a score from 1 to 5 for each indicated statement, where: 5 is strongly agree, 4 agree, 3 neutral, 2 disagree and 1 strongly disagree. Otherwise, please follow the specific instructions.

\section{Relevance and Difficulty Level}

1. The online case studies (descriptive texts) were relevant to basic wheelchair skills.
1
2
3
4
5

2. The online case studies (descriptive texts) were easy to understand.
1
2
3
4
5

3. The online case-based questions were relevant to basic wheelchair skills.

1

2

3

4

4. The online case-based questions were easy to understand. 


\section{Fidelity to Practice}

5. The online case-based questions format represented basic wheelchair tasks that I complete in my practice.
1
2
3
4
5

6. The in-person/video conference assessment format represented basic wheelchair tasks that I complete in my practice.
1
2
3
4
5

\section{Comparison of Two Approaches}

7. The two approaches were of equal difficulty.
1
2
3
4
5

8. If you selected a 3 or below, please indicate which approach was more difficult.

Please indicate which testing formats should be required to demonstrate competency (i.e., both knowledge and skill) in basic wheelchair service provision (check all that apply): 
Basic Knowledge Test (Online 75 question test that was a pre-requisite for this pilot)

Basic Skills Case Study Questionnaire (Online case studies \& case-based questions)

Basic Skills Assessment (Video conference assessment)

- Did we miss any relevant Domain/Testable Skill? Please provide your comments in the following table, according to the particular domain, or write below any general area we missed that may cross several domains.

\begin{tabular}{|c|c|c|c|}
\hline Domain & Testable Skill & Checkbox & Comments \\
\hline \multirow[t]{3}{*}{ Assessment } & Interview & & \\
\hline & Basic measurements & & \\
\hline & Observation & & \\
\hline \multirow[t]{2}{*}{ Fitting } & Pressures & & \\
\hline & Fitting checks & & \\
\hline \multirow[t]{2}{*}{ Prescription } & Specific checks & & \\
\hline & Cushion & & \\
\hline \multirow{2}{*}{ Process } & Documentation & & \\
\hline & Professionalism & & \\
\hline \multirow[t]{3}{*}{ Product preparation } & Assembly and adjustment & & \\
\hline & Safety checks & & \\
\hline & Cushion check & & \\
\hline \multirow[t]{3}{*}{ User training } & Mobility training and skills & & \\
\hline & Transfer skills & & \\
\hline & Trouble shooting & & \\
\hline Follow up & Care instructions & & \\
\hline
\end{tabular}

- Do you have any additional feedback to help us accomplish our goal of developing and piloting a basic wheelchair skills assessment? 
- Can we please follow up with you for any clarification on your responses or additional feedback?

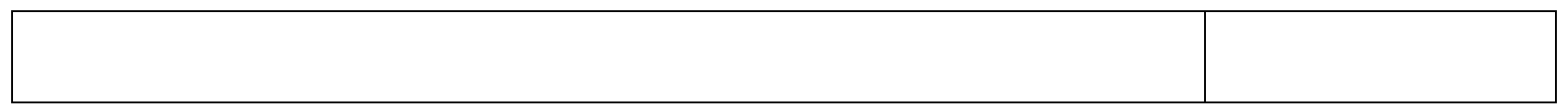




\section{Bibliography}

ATscale. (2018). Global Partnership for Assistive Technology. Retrieved from: https://atscale2030.org/overview

Boninger, M. L., \& Stripling, T. E. (2007). Preserving Upper-Limb Function in Spinal Cord Injury. Archives of Physical Medicine and Rehabilitation, 88(6), 817. doi: 10.1016/j.apmr.2007.03.033

Burrola-Mendez, Y., Bonilla-Escobar, F. J., Goldberg, M., \& Pearlman, J. (2019). Comparing the effectiveness of a hybrid and in-person courses of wheelchair service provision knowledge: A controlled quasi-experimental study in India and Mexico. Plos One, 14(5). doi: 10.1371/journal.pone.0217872

Burrola-Mendez, Y., Goldberg, M., Gartz, R., \& Pearlman, J. (2018). Development of a Hybrid Course on Wheelchair Service Provision for clinicians in international contexts. Plos One, 13(6). doi: 10.1371/journal.pone.0199251

Chaves, E.S., Boninger, M.L., Cooper, R., Fitzgerald, S.G., Gray, D.B., \& Cooper, R.A. (2004). Assessing the influence of wheelchair technology on perception of participation in spinal cord injury. Archives of physical medicine and rehabilitation, 85(11):1854-8. doi: 10.1016/j.apmr.2004.03.033

Cohen, D., Sevdalis, N., Patel, V., Taylor, M., Lee, H., Vokes, M., ... Darzi, A. (2013). Tactical and operational response to major incidents: Feasibility and reliability of skills assessment using novel virtual environments. Resuscitation, 84(7), 992-998. doi: 10.1016/j.resuscitation.2012.12.011

Crane, B., Hobson, D. (2003). No room for discomfort. Rehab Manag, 16(1):30-5

Fung, K. H., Rushton, P. W., Gartz, R., Goldberg, M., Toro, M. L., Seymour, N., \& Pearlman, J. (2017). Wheelchair service provision education in academia. African Journal of Disability, 6. doi: 10.4102/ajod.v6i0.340

Fung, K., Miller, T., Rushton, P. W., Goldberg, M., Toro, M. L., Seymour, N., \& Pearlman, J. (2019). Integration of wheelchair service provision education: current situation, facilitators and barriers for academic rehabilitation programs worldwide. Disability and Rehabilitation: Assistive Technology, 1-10. doi: 10.1080/17483107.2019.1594408

Gartz, R., Goldberg, M., Miles, A., Cooper, R., Pearlman, J., Schmeler, M., ... Hale, J. (2016). Development of a contextually appropriate, reliable and valid basic Wheelchair Service Provision Test. Disability and Rehabilitation: Assistive Technology, 12(4), 333-340. doi: 10.3109/17483107.2016.1166527 
Geyer, M. J., Brienza, D. M., Karg, P., Trefler, E., \& Kelsey, S. (2001). A Randomized Control Trial to Evaluate Pressure-Reducing Seat Cushions for Elderly Wheelchair Users. Advances in Skin \& Wound Care, 14(3), 120-129. doi: 10.1097/00129334-20010500000008

Goldberg, M. (2014). Comparative Effectiveness of Online Training in Assistive Technology and its Use for Development of Rehabilitation Professionals' Interprofessionality and Reflectiveness. University of Pittsburgh

Goldberg, M., Pearlman, J., Rushton, P., \& Cooper, R. (2018). The International Society of Wheelchair Professionals (ISWP): A resource aiming to improve wheelchair services worldwide. British Journal of Occupational Therapy, 81(12), 671-672. doi: $10.1177 / 0308022618793056$

Gowran, R.J., Bray, N., Goldberg, M.R., Rushton, P.W., Abou Saab, M.B., Constantine, D., Ghosh, R., \& Pearlman, J. (2019). Global challenges to access appropriate wheelchairs. Global perspectives on assistive technology, page 175

Greer, N., Brasure, M., \& Wilt, T. J. (2012). Wheeled Mobility (Wheelchair) Service Delivery: Scope of the Evidence. Annals of Internal Medicine, 156(2), 141. doi: 10.7326/00034819-156-2-201201170-00010

Kirby, R. L. (2016). Wheelchair Skills Assessment and Training. doi: 10.1201/9781315369389

Kirby, R., Swuste, J., Dupuis, D. J., Macleod, D. A., \& Monroe, R. (2002). The Wheelchair Skills Test: A pilot study of a new outcome measure. Archives of Physical Medicine and Rehabilitation, 83(1), 10-18. doi: 10.1053/apmr.2002.26823

Kirby, R.L., Worobey, L.A., Shea, M., Pedersen, J.P., \& Cowan, R. (2019). Effectiveness of remote asynchronous wheelchair skills training for clinicians. RESNA 2019 conference abstracts, Conference review; Pages 231-250

Mills, T. L., Holm, M. B., \& Schmeler, M. (2007). Test-Retest Reliability and Cross Validation of the Functioning Everyday With a Wheelchair Instrument. Assistive Technology, 19(2), 61-77. doi: 10.1080/10400435.2007.10131866

Munera, S., Goldberg, M., Kandavel, K., \& Pearlman, J. (2017). Development and evaluation of a wheelchair service provision training of trainers programme. African Journal of Disability, 6. doi: 10.4102/ajod.v6i0.360

Múnera, S., Pearlman, J., Toro, M., Worobey, L., Boninger, M., \& Cooper, R. A. (2019). Development and efficacy of an online wheelchair maintenance training program for wheelchair personnel. Assistive Technology, 1-7. doi: 10.1080/10400435.2019.1619632

Rehabilitation Engineering and Assistive Technology Society of North America. (2019). Assistive Technology Professional and Seating and Mobility Specialist. Retrieved from; https://www.resna.org/certification 
Rushton, P., Fung, K., Gauthier, M., Goldberg, M., Toro, M., Seymour, N. and Pearlman, J. (2020). Development of a toolkit for educators of the wheelchair service provision process: the Seating and Mobility Academic Resource Toolkit (SMART). Human Resources for Health, 18(1)

Smith, K. A., Setlhare, S., Decaen, A., Donoghue, A., Mensinger, J. L., Zhang, B., ... Meaney, P. A. (2019). Feasibility and preliminary validity evidence for remote video-based assessment of clinicians in a global health setting. Plos One, 14(8). doi: 10.1371/journal.pone.0220565

Toro, M. L., Bird, E., Oyster, M., Worobey, L., Lain, M., Bucior, S., ... Pearlman, J. (2017). Development of a wheelchair maintenance training programme and questionnaire for clinicians and wheelchair users. Disability and Rehabilitation: Assistive Technology, 12(8), 843-851. doi: 10.1080/17483107.2016.1277792

Toro, M. L., Eke, C., \& Pearlman, J. (2015). The impact of the World Health Organization 8steps in wheelchair service provision in wheelchair users in a less resourced setting: a cohort study in Indonesia. BMC Health Services Research, 16(1). doi: 10.1186/s12913016-1268-y

United Nations. (2006). Convention on the Rights of Persons with Disabilities. Retrieved from: https://www.un.org/development/desa/disabilities/convention-on-the-rights-of-personswith-disabilities.html

United Nations. (1948). The Universal Declaration of Human Rights. Retrieved from: http://www.un.org/en/universal-declaration-human-rights/

United States Agency International Development. (2018). Wheelchair Stakeholders' Meeting. Retrieved from: https://wheelchairnetwork.org/wp-content/uploads/2019/08/01a-WLWheelchair-Two-Pager-FINAL.pdf

Visagie, S., Mlambo, T., Veen, J. V. D., Nhunzv, C., Tigere, D., \& Scheffler, E. (2016). Impact of structured wheelchair services on satisfaction and function of wheelchair users in Zimbabwe. African Journal of Disability, 5(1). doi: 10.4102/ajod.v5i1.222

World Bank. (2018). Disability Inclusion. Retrieved from: http://www.worldbank.org/en/topic/disability

World Health Organization. (2008). Guidelines on the provision of manual wheelchairs in lessresourced settings. Retrieved from: https://www.who.int/disabilities/technology/wheelchairpackage/en/

World Health Organization. (2011). World Report on Disability. WHO web site (www.who.int)/WHO Press; page 29

World Health Organization. (2012). Wheelchair Training Service Package - Basic Level. Retrieved from: https://www.who.int/disabilities/technology/wheelchairpackage/en/ 
World Health Organization. (2013). Wheelchair Training Service Package - Intermediate Level. Retrieved from: https://www.who.int/disabilities/technology/wheelchairpackage/en/

World Health Organization. (2015). Wheelchair Training Service Package for Managers and Stakeholders. https://www.who.int/disabilities/technology/wheelchairpackage/en/

World Health Organization. (2017). Wheelchair Service Training of Trainers Package. Retrieved from: https://www.who.int/phi/implementation/assistive_technology/wheelchair-pubtraining/en/

World Health Organization. (2016). Priority Assistive Technology List. WHO web site (www.who.int)/WHO 